\title{
Genome-Wide Association Study and Selection Signatures Detect Genomic Regions Associated with Seed Yield and Oil Quality in Flax
}

\author{
Frank M. You ${ }^{1,2, *} \mathbb{C}^{\mathbb{D}}$, Jin Xiao ${ }^{1,3}$, Pingchuan $\mathrm{Li}^{1}{ }^{1}$, Zhen Yao ${ }^{2}$, Gaofeng Jia ${ }^{1,4}$, Liqiang $\mathrm{He}^{1}$, \\ Santosh Kumar ${ }^{5}$, Braulio Soto-Cerda ${ }^{6,7}$, Scott D. Duguid ${ }^{2}$, Helen M. Booker ${ }^{4}$ (D), \\ Khalid Y. Rashid ${ }^{2}$ and Sylvie Cloutier ${ }^{1,6, *}$ \\ 1 Ottawa Research and Development Centre, Agriculture and Agri-Food Canada, \\ Ottawa, ON K1A 0C6, Canada; xiaojin@njau.edu.cn (J.X.); lipingchuan@gmail.com (P.L.); \\ gaofeng.jia@usask.ca (G.J.); liqiang.he@canada.ca (L.H.) \\ 2 Morden Research and Development Centre, Agriculture and Agri-Food Canada, \\ Morden, MB R6M 1Y5, Canada; zhen.yao@canada.ca (Z.Y.); scott.duguid@agr.gc.ca (S.D.D.); \\ khalid.rashid@agr.gc.ca (K.Y.R.) \\ 3 Department of Agronomy, Nanjing Agricultural University, Nanjing 210095, China \\ 4 Crop Development Centre, University of Saskatchewan, Saskatoon, SK S7N 5A8, Canada; \\ helen.booker@usask.ca \\ 5 Brandon Research and Development Centre, Agriculture and Agri-Food Canada, \\ Brandon, MB R7A 5Y3, Canada; Santosh.kumar@agr.gc.ca \\ 6 Department of Plant Science, University of Manitoba, Winnipeg, MB R3T 2N2, Canada; braulio.soto@cgna.cl \\ 7 Agriaquaculture Nutritional Genomic Center, CGNA, Temuco 4871158, Chile \\ * Correspondence: frank.you@agr.gc.ca (F.M.Y.); sylvie.cloutuer@agr.gc.ca (S.C.); \\ Tel.: +1-613-759-1539 (F.M.Y.); +1-613-759-1744 (S.C.)
}

Received: 20 July 2018; Accepted: 3 August 2018; Published: 6 August 2018

\begin{abstract}
A genome-wide association study (GWAS) was performed on a set of 260 lines which belong to three different bi-parental flax mapping populations. These lines were sequenced to an averaged genome coverage of $19 \times$ using the Illumina Hi-Seq platform. Phenotypic data for 11 seed yield and oil quality traits were collected in eight year/location environments. A total of 17,288 single nucleotide polymorphisms were identified, which explained more than $80 \%$ of the phenotypic variation for days to maturity (DTM), iodine value (IOD), palmitic (PAL), stearic, linoleic (LIO) and linolenic (LIN) acid contents. Twenty-three unique genomic regions associated with 33 quantitative trait loci (QTL) for the studied traits were detected, thereby validating four genomic regions previously identified. The 33 QTL explained $48-73 \%$ of the phenotypic variation for oil content, IOD, PAL, LIO and LIN but only $8-14 \%$ for plant height, DTM and seed yield. A genome-wide selective sweep scan for selection signatures detected 114 genomic regions that accounted for $7.82 \%$ of the flax pseudomolecule and overlapped with the 11 GWAS-detected genomic regions associated with 18 QTL for 11 traits. The results demonstrate the utility of GWAS combined with selection signatures for dissection of the genetic structure of traits and for pinpointing genomic regions for breeding improvement.
\end{abstract}

Keywords: flax; genome-wide association study (GWAS); selective sweep; genotyping by sequencing (GBS); bi-parental population; single nucleotide polymorphism (SNP); seed yield; plant height; maturity; fatty acid composition

\section{Introduction}

Flax (Linum usitatissimum L., $2 n=2 x=30$ ) is a self-pollinating annual crop from the Linaceae family. It is a dual-purpose crop grown for its seed oil or stem fiber, resulting in two morphotypes: 
linseed and fiber. The linseed or flaxseed morphotype is rich in oil (40-50\%) containing five main fatty acids: palmitic (PAL, C16:0, 6\%), stearic (STE, C18:0, 2.5\%), oleic (OLE, C18:1 ${ }^{\Delta 9}, \sim 19 \%$ ), linoleic (LIO, C18:2 $2^{\Delta 9}, 12, \sim 13 \%$ ), and linolenic (LIN, C18:3 $3^{\Delta 9}, 12,15, \sim 55 \%$ ) [1,2]. Because of its high LIN content, linseed is the richest plant source of omega-3 fatty acid which is beneficial for reducing blood cholesterol levels and mitigating heart diseases in humans [3,4]. The same attributes make it ideal as industrial oil for use in paints, linoleum flooring, inks, soaps and varnishes [4].

Linseed breeding has focused on high seed yield (YLD), high oil content (OIL), and either high or low LIN content. Low LIN (2-4\%) and high LIO (65-70\%) lines have been developed through mutation breeding. NuLin ${ }^{\mathrm{TM}} 50$ with $67.8 \%$ LIN (http:/ / www.viterra.ca) and Omégalin with 65.8\% (http:/ / www.terredelin.com) are examples of high LIN linseed cultivars currently registered. Extremely low LIN lines such as Linola ${ }^{\mathrm{TM}}$ or Solin ${ }^{\mathrm{TM}}$ improve oxidative stability, making such cultivars suitable for the fabrication of margarine [3]. Since 1910, a total of 82 flax cultivars have been released in Canada [5]. These cultivars and elite breeding lines provide diverse genetic materials for dissecting the genetic architecture of oil biosynthesis and yield related traits in linseed.

Several methods can be used to dissect the genetic architecture of crop traits. QTL or linkage mapping uses bi-parental populations to identify loci responsible for trait variation between parents based on a recombination-based genetic linkage map [6]. Bi-parental populations, such as $\mathrm{F}_{2}$, recombinant inbred line (RIL), doubled haploid (DH) and backcross (BC) populations, are the most widely used genetic resources for mapping QTL for traits of interest in self-fertilizing crops, including flax [7-12]. While bi-parental populations are easy to develop and have power for QTL detection, only the a limited number of alleles from the parental genotypes are analyzed in a single population, resulting in a narrow genetic base and low representation of allelic diversity [13]. In addition, genetic recombination is limited in these populations [14]. To increase the QTL dissection power, attempts have been made to expand the genetic diversity through other multiple-parent population types, such as nested association mapping (NAM) populations [15-17] and multi-parent advanced generation intercross (MAGIC) populations [18-25], while retaining the advantages of association mapping and bi-parental populations. However, the development of such populations requires careful planning and time. Natural populations that possess tremendous phenotypic diversity can be advantageous in genome-wide association study (GWAS) with various molecular markers in plants and animals [26-31]. Association mapping using a diverse germplasm panel overcomes the phenotypic diversity limitation of bi-parental populations, thereby increasing the QTL mapping power [32] but is impeded by low detection power of association of rare alleles. GWAS usually uses a natural population to investigate wider phenotypic variation for complex traits by taking advantage of ancient genetic recombination events in populations [33].

GWAS may be complemented by performing genome-wide selective sweep scan (GW3S) which identifies selection signatures that are beneficial for plant adaptation. A selective sweep is the reduction or elimination of variation among the nucleotides near a new beneficial mutation. Following strong positive natural selection or artificial selection during domestication or breeding, selective sweeps affect nearby linked alleles [34]. Ancient selective sweeps are relevant to natural evolution and domestication of crop species that are subjected to natural and artificial selective pressures and forced to adapt rapidly to new environments and thus drive speciation [35]. Breeding selects favorable alleles and retains them in new cultivars. These signatures of selection can be detected by a cross-population comparison approach [34]. Recent studies demonstrated that genomic regions that exhibit selection signatures are also enriched for genes associated with biologically important traits [36-40]. Thus, detection of selection signatures is emerging as an additional approach to identify and validate novel gene-trait associations [41].

Genetic regions associated with storage oil biosynthesis in flax have been studied based on QTL mapping using bi-parental populations. Several QTL responsible for oil content and fatty acid composition have been mapped in independent studies including the three populations used herein. The first population (BM) of $243 \mathrm{~F}_{2: 6}$ recombinant inbred lines (RILs) from a cross between the Canadian 
linseed varieties CDC Bethune and Macbeth was used for a linkage mapping study and detected three QTL each for OLE and STE, two each for LIO and IOD, and one each for PAL, LIN and OIL with several QTL co-locating at the same locus [8]. The second population (EV) was a cross between E1747 and Viking. The third population (SU) was a cross between SP2047 (a yellow-seeded Solin ${ }^{\mathrm{TM}}$ line with 2-4\% LIN) and UGG5-5 (a brown-seeded flax line with 63-66\% LIN) and comprised of 78 lines generated through DH method. It was used in a linkage mapping study using simple sequence repeat (SSR) markers which identified QTL for LIO, LIN and iodine value (IOD) co-locating on LG7 and LG16, and a QTL for PAL on LG9 [7]. The linkage-based studies from these populations provided numerous QTL for important traits but the QTL were generally far from the markers and poorly delimited because of the low resolution of the genetic maps $[18,19,42]$.The three bi-parental populations were also used to construct a consensus genetic map [43], and to perform genomic selection [44] primarily using SSR markers. Because the three populations have been simultaneously phenotyped for several common agronomic and seed oil quality traits in the same environments (years/locations), we designed the present study to test the efficiency of the combined bi-parental population approach for GWAS and GW3S to detect genomic regions associated with seed yield and seed oil quality traits using genotyping by sequencing (GBS).

\section{Results}

\subsection{Re-Sequencing and Genome-Wide SNPs}

In the present study, a set of 260 genotypes (97 from the recombinant inbreeding line (RIL) population from a cross between CDC Bethune and Macbeth (BM), 91 from the RIL population from a cross between E1747 and Viking (EV) and 72 from the doubled haploid population from a cross between SP2047 and UGG5-5 (SU) along with the 5 of 6 parents except for the reference CDC Bethune) were re-sequenced using GBS to identify genome-wide single nucleotide polymorphism (SNP) markers on the chromosome-based flax pseudomolecules [45]. An average of $\sim 57.7$ million paired end reads were generated for each individual, corresponding to $5754 \mathrm{Mb}$ sequences or $19.2 \times$ genome equivalents of the reference scaffolds ( $302 \mathrm{Mb})$ [46] (Table S1). Paired-end reads of each genotype were aligned to the flax scaffolds [46], resulting in a total of 536,186 SNPs. After filtering off SNPs with minor allele frequency (MAF) $<0.05$ and genotyping rate $<60 \%[47,48], 17,288$ SNPs were retained on the flax pseudomolecules [45] (Table S2). Out of these, 15,284 segregated in BM, 15,397 in EV and 7568 in SU. The SNPs were mostly uniformly distributed across all 15 chromosomes (chr), ranging from 601 on chr11 to 1572 on chr13 (Figure 1, Table S2). Approximately 71.1\% of all SNPs were located in intergenic regions, $16.2 \%$ were in introns and $12.7 \%$ were in exons (Table S2). These SNPs were used for further population structure analysis, GWAS and GW3S.

\subsection{Whole-Genome Pattern of LD}

The LD and LD decay rates were analyzed for each population separately as well as the merged population using the filtered SNP data. The physical distances of pair-wise SNPs at which the LD $r^{2}$ dropped to half were $1242,223,728$ and $272 \mathrm{~kb}$ for BM, EV, SU and merged populations respectively. This indicated substantial variation in LD decay rate across populations (Figure 2). The average LD $r^{2}$ of $\mathrm{BM}, \mathrm{EV}, \mathrm{SU}$, and merged populations were $0.37,0.26,0.28$ and 0.30 , respectively, with the number of haplotype blocks for each population estimated at 599, 648, 206 and 1205, respectively (Table S3). 

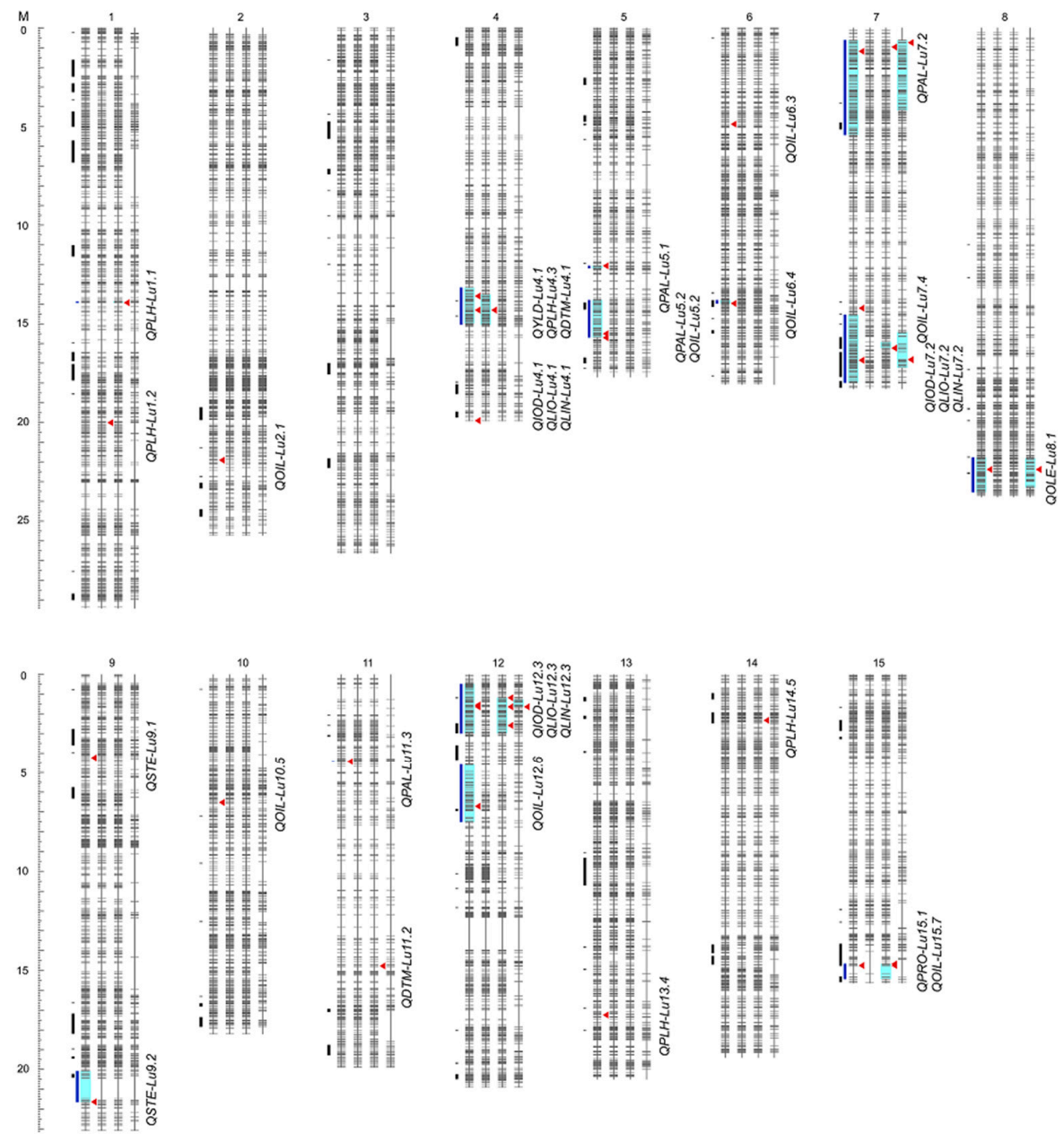

Figure 1. Distribution of 17,288 SNPs, 114 selective sweeps and 33 QTL on the 15 chromosomes of flax for each of three bi-parental populations BM, EV and SU and, for the merged population $(\mathrm{BM}+\mathrm{EV}+\mathrm{SU})$. Four vertical bars from left to right for each chromosome represent the $\mathrm{BM}+\mathrm{EV}+\mathrm{SU}$, BM, EV and SU populations, respectively. Short horizontal lines on bars represent SNPs. QTL regions are highlighted in cyan and by vertical blue lines. Red triangles identify QTL's peak SNP. Selective sweeps are represented by short vertical black lines.

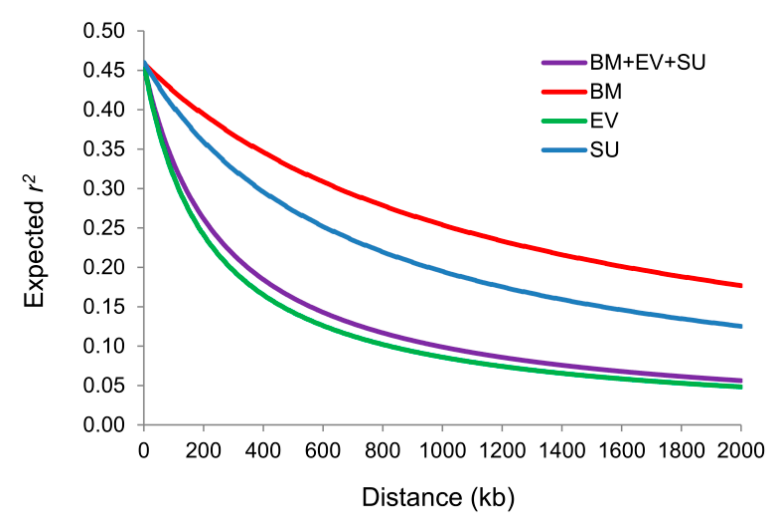

Figure 2. Intra-chromosome LD $\left(r^{2}\right)$ decay of SNP pairs over the entire flax genome as a function of physical distances $(\mathrm{kb})$ of pair-wise SNPs for the three individual and merged populations. The curves are drawn based on a fitted non-linear model (see Section 4.2). 


\subsection{Genetic Diversity and Population Structure}

Nucleotide diversity $(\pi)$ was estimated at 41.52, 38.26 and 3.95 for the BM, EV and SU populations, respectively (Table 1), and was consistent with the number of SNPs identified from the three populations. A strong population-differentiation $\left(F_{s t}\right)$ was observed at 0.44 between BM and SU and 0.48 between EV and SU. However, $F_{s t}$ was weaker at 0.04 between the BM and EV (Table 1).

Table 1. Genetic differentiation $\left(F_{s t}\right)$ between three bi-parental (upper triangle elements) and nucleotide diversity $(\pi)$ within these populations (diagonal elements).

\begin{tabular}{cccc}
\hline Population & BM & EV & SU \\
\hline BM & 41.52 & 0.04 & 0.44 \\
EV & & 38.26 & 0.48 \\
SU & & & 3.95
\end{tabular}

BM: CDC Bethune/Macbeth; EV: E1747/Viking; SU: SP2047/UGG5-5.

The genetic structure within the merged population was assessed based on the 17,288 SNP loci from the 260 individuals using two methods: principal component analysis (PCA) and discriminant analysis for principal components (DAPC). Bi-plots of the first three principal components of the PCA showed five distinct clusters (Figure 3a,b). The BM (BM1 and BM2) and EV (EV1 and EV2) populations each contained two sub-populations, while SU produced a single cluster. DAPC corroborated the same five clusters (Figure 3c,d). Therefore, a DAPC Q matrix based on the five clusters was generated and used as covariates to assess the population stratification in GWAS and phenotypic variation explained by the SNPs.
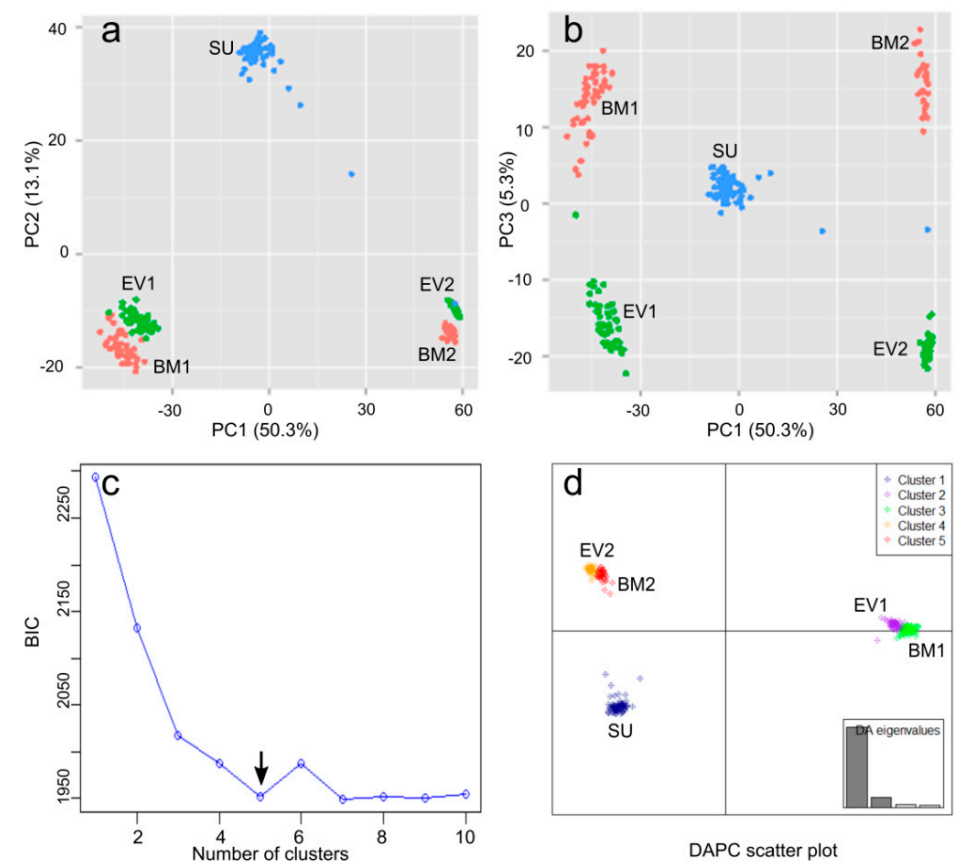

Figure 3. Principal component analysis (PCA) and discriminant analysis of principal components (DAPC) of the 260 individuals in three bi-parental populations (BM, EV and SU) based on 17,288 SNPs. (a) Bi-plot of the first and second principal components (PCs); (b) Bi-plot of the first and third PCs; (c) $k$-means clustering analysis based on 100 chosen PCs shows that the optimal number of clusters $(k)$ is 5, that is where the Bayesian information criterion (BIC) is lowest (arrow); (d) DAPC scatter plot. Percentages in parentheses in the axis titles of (a) and (b) represent the variance explained by the respective PCs. Individuals from the BM and EV populations grouped into two subpopulations each, $\mathrm{BM} 1$ and BM2, and EV1 and EV2, respectively. 


\section{4. $h_{S N P}^{2}$}

Phenotypic variation of traits was largely explained by SNPs in the three individual and the merged populations (Table 2). The average $h_{S N P}^{2}$ for all 11 traits was 0.51 . The largest $h_{S N P}^{2}$ values among the four populations ranged from 0.45 (YLD) to 0.90 (PAL). More than $80 \%$ of the phenotypic variation in one of the populations was explained by identified SNPs for days to maturity (DTM), IOD, PAL, STE, LIO and LIN. The $h_{S N P}^{2}$ varied from one population to another depending on the genetic variation between the two parents. For SU, little or no phenotypic variation was explained by SNPs for DTM, plant height (PLH) and STE. For EV, a relatively low phenotypic variation $\left(h_{S N P}^{2}<0.1\right)$ was explained by SNPs for STE and OLE.

Table 2. Phenotypic variation explained by all SNPs $\left(h_{S N P}^{2}\right)$ and identified QTL $\left(h_{G W A S}^{2}\right)$ for 11 traits in different populations.

\begin{tabular}{|c|c|c|c|c|}
\hline Trait & Population & $h_{S N P}^{2} \pm s$ & No. QTL & $h_{G W A S}^{2} \pm s$ \\
\hline \multirow{4}{*}{ YLD } & $\mathrm{BM}+\mathrm{EV}+\mathrm{SU}$ & $0.43 \pm 0.12$ & 1 & $0.14 \pm 0.09 \S$ \\
\hline & $\mathrm{BM}$ & $0.22 \pm 0.25$ & & \\
\hline & $\mathrm{EV}$ & $0.15 \pm 0.24$ & & \\
\hline & SU & $0.45 \pm 0.21$ & & \\
\hline \multirow{4}{*}{ PLH } & $\mathrm{BM}+\mathrm{EV}+\mathrm{SU}$ & $0.53 \pm 0.12$ & 1 & $0.08 \pm 0.11$ \\
\hline & $\mathrm{BM}$ & $0.76 \pm 0.12$ & 2 & $0.21 \pm 0.15$ \\
\hline & $\mathrm{EV}$ & $0.76 \pm 0.14$ & 2 & $0.22 \pm 0.18$ \\
\hline & SU & $0.06 \pm 0.20$ & & \\
\hline \multirow{4}{*}{ DTM } & $\mathrm{BM}+\mathrm{EV}+\mathrm{SU}$ & $0.43 \pm 0.13$ & 1 & $0.10 \pm 0.07$ \\
\hline & $\mathrm{BM}$ & $0.81 \pm 0.11$ & 1 & $0.18 \pm 0.13$ \\
\hline & $\mathrm{EV}$ & $0.36 \pm 0.24$ & 1 & $0.18 \pm 0.22$ \\
\hline & SU & $0.00 \pm 0.20$ & & \\
\hline \multirow{4}{*}{ PRO } & $\mathrm{BM}+\mathrm{EV}+\mathrm{SU}$ & $0.51 \pm 0.11$ & 1 & $0.12 \pm 0.16$ \\
\hline & $\mathrm{BM}$ & $0.52 \pm 0.20$ & & \\
\hline & EV & $0.34 \pm 0.23$ & 1 & $0.09 \pm 0.12$ \\
\hline & SU & $0.58 \pm 0.19$ & & \\
\hline \multirow{4}{*}{ OIL } & $\mathrm{BM}+\mathrm{EV}+\mathrm{SU}$ & $0.66 \pm 0.09$ & 7 & $0.62 \pm 0.14$ \\
\hline & $\mathrm{BM}$ & $0.46 \pm 0.22$ & & \\
\hline & $\mathrm{EV}$ & $0.39 \pm 0.21$ & 1 & $0.08 \pm 0.08$ \\
\hline & SU & $0.70 \pm 0.15$ & & \\
\hline \multirow{4}{*}{ IOD } & $\mathrm{BM}+\mathrm{EV}+\mathrm{SU}$ & $0.80 \pm 0.06$ & 3 & $0.57 \pm 0.10$ \\
\hline & $\mathrm{BM}$ & $0.49 \pm 0.19$ & & \\
\hline & EV & $0.78 \pm 0.12$ & 2 & $0.51 \pm 0.14$ \\
\hline & SU & $0.66 \pm 0.17$ & 2 & $0.35 \pm 0.18$ \\
\hline \multirow{4}{*}{ PAL } & $\mathrm{BM}+\mathrm{EV}+\mathrm{SU}$ & $0.79 \pm 0.06$ & 4 & $0.48 \pm 0.11$ \\
\hline & $\mathrm{BM}$ & $0.12 \pm 0.26$ & & \\
\hline & EV & $0.55 \pm 0.20$ & 1 & $0.09 \pm 0.11$ \\
\hline & SU & $0.90 \pm 0.07$ & 1 & $0.56 \pm 0.18$ \\
\hline \multirow{4}{*}{ STE } & $\mathrm{BM}+\mathrm{EV}+\mathrm{SU}$ & $0.21 \pm 0.15$ & 2 & $0.41 \pm 0.19$ \\
\hline & $\mathrm{BM}$ & $0.85 \pm 0.09$ & & \\
\hline & $\mathrm{EV}$ & $0.02 \pm 0.14$ & & \\
\hline & SU & $0.00 \pm 0.22$ & 1 & \\
\hline \multirow{4}{*}{ OLE } & $\mathrm{BM}+\mathrm{EV}+\mathrm{SU}$ & $0.55 \pm 0.10$ & 1 & $0.16 \pm 0.13$ \\
\hline & $\mathrm{BM}$ & $0.36 \pm 0.22$ & & \\
\hline & $\mathrm{EV}$ & $0.09 \pm 0.25$ & & \\
\hline & $\mathrm{SU}$ & $0.72 \pm 0.16$ & 1 & $0.20 \pm 0.19$ \\
\hline
\end{tabular}


Table 2. Cont.

\begin{tabular}{ccccc}
\hline Trait & Population & $h_{\text {SNP }}^{2} \pm s$ & No. QTL & $h_{\text {GWAS }}^{2} \pm s$ \\
& $\mathrm{BM}+\mathrm{EV}+\mathrm{SU}$ & $0.80 \pm 0.06$ & 3 & $0.73 \pm 0.07$ \\
$\mathrm{LIO}$ & $\mathrm{BM}$ & $0.54 \pm 0.20$ & & \\
& $\mathrm{EV}$ & $0.75 \pm 0.13$ & 2 & $0.54 \pm 0.14$ \\
& $\mathrm{SU}$ & $0.66 \pm 0.17$ & 2 & $0.36 \pm 0.18$ \\
\hline \multirow{4}{*}{ LIN } & $\mathrm{BM}+\mathrm{EV}+\mathrm{SU}$ & $0.80 \pm 0.06$ & 3 & $0.56 \pm 0.09$ \\
& $\mathrm{BM}$ & $0.49 \pm 0.19$ & & \\
& $\mathrm{EV}$ & $0.76 \pm 0.13$ & 2 & $0.55 \pm 0.14$ \\
& $\mathrm{SU}$ & $0.66 \pm 0.17$ & 2 & $0.36 \pm 0.18$ \\
\hline
\end{tabular}

YLD: seed yield; PLH: plant height; DTM: days to maturity; PRO: protein content; OIL: oil content; IOD: iodine value; PAL: palmitic acid content; STE: stearic acid content; OLE: oleic acid content; LIO: linoleic acid content; LIN: linolenic acid content; BM: CDC Bethune/Macbeth; EV: E1747/Viking; SU: SP2047/UGG5-5. ${ }^{\S} h_{G W A S}^{2}$ of YLD was estimated based on the phenotypes in a single environment (Morden/2012). For all other traits, $h_{G W A S}^{2}$ was estimated based on the BLUP estimates of phenotypes.

\subsection{QTL Identified from 11 Traits}

Using the best linear unbiased prediction (BLUP) values of phenotyping data collected from six to eight year/location environments with both generalized linear model (GLM) and mixed linear model (MLM), we identified a total of 33 QTL for 11 traits, one for YLD, eight for OIL, five for PLH, four for PAL, three each for IOD, LIO, and LIN, two each for DTM and STE, and one each for protein content (PRO) and OLE (Table 3, Figure 1, Figures S1 and S2). Thirty-one of the 33 QTL were detected using GLM and 13 with MLM (Tables S4 and S5). Of these latter 13, two QTL (QTL 18 for IOD and QTL 31 for LIN) were detected only by MLM, while the remaining 11 were identified by both MLM and GLM (Table S4).

Out of 33 QTL identified, 12, 6, 3 and 27 were from EV, SU, BM and merged population, respectively. Only six QTL were detected exclusively from two individual populations, including four (QTL 2 and 6 for PLH, QTL 8 for DTM and QTL 17 for OIL) from EV and two (QTL 3 and 4 for PLH) from BM. Eighteen were identified exclusively from the merged population. Ten QTL were detected simultaneously from the merged population and one or more individual populations (Tables S4 and S5).

QTL for YLD (QTL 1) was identified only in two environments (2010/Morden and 2012/Saskatoon) (Figure S2) but not in other environments or using BLUP estimates over the six year/location environments. We also performed GWAS for all other traits with phenotypic data from individual environments and obtained similar results with the QTL identified using BLUP values over multiple environments (Table S6).

\subsection{QTL Effect Significance}

To validate the QTL, we tested statistical significance of difference of phenotypes between two contrasting haplotype pairs for each QTL in the merged and individual populations and in different year/location environments. QTL effect differences between two contrasting haplotype pairs for all 33 QTL were significant (Figure 4, Table S7). We also assessed relationship of the number of pyramiding positive-effect QTL in individuals with trait phenotypes. Significant linear relations for all eight traits which had two or more QTL identified in this study were observed, showing primarily additive or accumulative QTL effects (Figure 5). 
Table 3. QTL and associated gene candidates.

\begin{tabular}{|c|c|c|c|c|c|c|c|c|c|c|c|}
\hline Trait & QTL No. & QTL Name & Chr. & Start Position (bp) & End Position (bp) & XP-CLR Score & $\begin{array}{c}\text { Known QTL or } \\
\text { Marker }\end{array}$ & $\begin{array}{l}\text { Candidate } \\
\text { Gene IDs }\end{array}$ & $\begin{array}{l}\text { Candidate Gene } \\
\text { Location (bp) }\end{array}$ & $\begin{array}{l}\text { Candidate Gene } \\
\text { Name }\end{array}$ & Gene Annotation \\
\hline YLD & 1 & QYLD-Lu4.1 & 4 & $13,594,936$ & $14,968,389$ & 12.54 & QYld.BM.crc-LG4 ${ }^{\text {a }}$ & & & & \\
\hline \multirow{10}{*}{ PLH } & 2 & QPLH-Lu1.1 & 1 & $13,887,715$ & $13,930,292$ & & & & & & \\
\hline & \multirow[t]{2}{*}{3} & \multirow[t]{2}{*}{ QPLH-Lu1.2 } & \multirow[t]{2}{*}{1} & \multirow[t]{2}{*}{$20,012,490$} & \multirow[t]{2}{*}{$20,012,490$} & & & Lus10020835 & $19,610,837$ & BRI1 [49] & $\begin{array}{l}\text { Leucine-rich receptor-like protein kinase family } \\
\text { protein }\end{array}$ \\
\hline & & & & & & & & Lus10020865 & $19,790,777$ & GA2 [49] & $\begin{array}{l}\text { Terpenoid cyclases/Protein prenyltransferases } \\
\text { superfamily protein }\end{array}$ \\
\hline & \multirow{5}{*}{4} & \multirow{5}{*}{ QPLH-Lu4.3 } & \multirow{5}{*}{4} & \multirow{5}{*}{$14,305,982$} & \multirow{5}{*}{$15,042,104$} & \multirow{5}{*}{12.54} & & Lus10034358 & $14,006,288$ & BIM2 [49] & BES1-interacting Myc-like protein 2 \\
\hline & & & & & & & & Lus10041435 & $14,157,752$ & MYB62 [49] & Myb domain protein 62 \\
\hline & & & & & & & & Lus10041481 & $14,398,338$ & LMCO4 [49] & Laccase/Diphenol oxidase family protein \\
\hline & & & & & & & & Lus10041794 & $15,920,170$ & ROT3 [49] & Cytochrome P450 superfamily protein \\
\hline & & & & & & & & Lus10041801 & $15,948,434$ & WAT1 [49] & Walls Are Thin 1 \\
\hline & 5 & QPLH-Lu13.4 & 13 & $17,243,884$ & $17,243,884$ & & & Lus10030567 & $18,680,474$ & GA2OX8 [49] & Gibberellin 2-oxidase 8 \\
\hline & 6 & QPLH-Lu13.5 & 14 & $2,320,469$ & $2,320,469$ & 40.61 & & Lus10021395 & $3,647,029$ & НСТ [49] & $\begin{array}{l}\text { Hydroxycinnamoyl-CoA shikimate/quinate } \\
\text { hydroxycinnamoyl transferase }\end{array}$ \\
\hline \multirow{8}{*}{ DTM } & \multirow{7}{*}{7} & \multirow{7}{*}{ QDTM-Lu4.1 } & \multirow{7}{*}{4} & \multirow{7}{*}{$13,171,757$} & \multirow{7}{*}{$15,042,104$} & \multirow{7}{*}{12.54} & \multirow{7}{*}{ QDm.BM.crc-LG4 ${ }^{\mathrm{a}}$} & Lus10015766 & $13,094,864$ & $F L C[50]$ & $\begin{array}{l}\text { K-box region and MADS-box transcription } \\
\text { factor family protein }\end{array}$ \\
\hline & & & & & & & & Lus10034461 & $13,434,121$ & CDF3 [50] & Cycling DOF factor 3 \\
\hline & & & & & & & & Lus10034370 & $13,933,421$ & $A P 1[50]$ & $\begin{array}{l}\text { K-box region and MADS-box transcription } \\
\text { factor family protein }\end{array}$ \\
\hline & & & & & & & & Lus10041483 & $14,411,103$ & PFT1 [50] & $\begin{array}{c}\text { Phytochrome and flowering time regulatory } \\
\text { protein (PFT1) }\end{array}$ \\
\hline & & & & & & & & Lus10041500 & $14,512,085$ & ATAN11 [50] & $\begin{array}{l}\text { Transducin/WD40 repeat-like superfamily } \\
\text { protein }\end{array}$ \\
\hline & & & & & & & & Lus10041540 & $14,716,950$ & RGL1 [50] & RGA-like 1 \\
\hline & & & & & & & & Lus10041595 & $14,966,739$ & $A P 2[50]$ & $\begin{array}{c}\text { Integrase-type DNA-binding superfamily } \\
\text { protein }\end{array}$ \\
\hline & 8 & QDTM-Lu11.2 & 11 & $14,768,686$ & $14,768,686$ & & & & & & \\
\hline PRO & 9 & QPRO-Lu15.1 & 15 & $14,746,288$ & $14,746,310$ & 8.50 & & Lus10030671 & $22,732,660$ & WRI [50] & $\begin{array}{l}\text { Integrase-type DNA-binding superfamily } \\
\text { protein }\end{array}$ \\
\hline
\end{tabular}


Table 3. Cont

\begin{tabular}{|c|c|c|c|c|c|c|c|c|c|c|c|}
\hline Trait & QTL No. & QTL Name & Chr. & Start Position (bp) & End Position (bp) & XP-CLR Score & $\begin{array}{c}\text { Known QTL or } \\
\text { Marker }\end{array}$ & $\begin{array}{l}\text { Candidate } \\
\text { Gene IDs }\end{array}$ & $\begin{array}{l}\text { Candidate Gene } \\
\text { Location (bp) }\end{array}$ & $\begin{array}{c}\text { Candidate Gene } \\
\text { Name }\end{array}$ & Gene Annotation \\
\hline \multirow{8}{*}{ OIL } & 10 & QOIL-Lu2.1 & 2 & $21,913,720$ & $21,913,720$ & & & & & & \\
\hline & 11 & QOIL-Lu5.2 & 5 & $15,704,607$ & $15,705,039$ & & & & & & \\
\hline & 12 & QOIL-Lu6.3 & 6 & $4,879,632$ & $4,879,632$ & & & & & & \\
\hline & 13 & QOIL-Lu6.4 & 6 & $13,799,180$ & $13,970,951$ & 50.58 & & & & & \\
\hline & 14 & QOIL-Lu7.4 & 7 & $14,209,179$ & $14,209,179$ & & & & & & \\
\hline & 15 & QOIL-Lu10.5 & 10 & $6,517,448$ & $6,517,448$ & & & & & & \\
\hline & 16 & QOIL-Lu12.6 & 12 & $4,591,214$ & $7,491,405$ & 27.77 & & & & & \\
\hline & 17 & QOIL-Lu15.7 & 15 & $14,665,900$ & $15,429,055$ & 8.89 & & Lus10039906 & $19,833,852$ & KCS14-2 [51] & 3-ketoacyl-CoA synthase \\
\hline \multirow{4}{*}{ IOD } & 18 & QIOD-Lu4.1 & 4 & $19,909,467$ & $19,909,467$ & & & Lus10039906 & $19,833,852$ & KCS14-2 [51] & 3-ketoacyl-CoA synthase \\
\hline & 19 & QIOD-Lu7.2 & 7 & $15,346,458$ & $17,977,459$ & 45.70 & QIOD.crc-LG7 b & Lus10038321 & $16,089,922$ & FAD3a [52] & Fatty acid desaturase \\
\hline & \multirow{2}{*}{20} & \multirow{2}{*}{ QIOD-Lu12.3 } & \multirow{2}{*}{12} & \multirow{2}{*}{489,561} & \multirow{2}{*}{$2,981,642$} & \multirow{2}{*}{106.22} & \multirow{2}{*}{ QIOD.crc-LG16 b } & Lus10036184 & $1,035,336$ & FAD3b [52] & Fatty acid desaturase \\
\hline & & & & & & & & Lus10023359 & $1,729,292$ & FAH1 [50] & Fatty acid hydroxylase 1 \\
\hline \multirow{6}{*}{ PAL } & 21 & QPAL-Lu5.1 & 5 & $12,062,376$ & $12,182,441$ & & & Lus10029880 & $12,062,376$ & KCS12-3 [51] & 3-ketoacyl-CoA synthase \\
\hline & 22 & QPAL-Lu5.2 & 5 & $13,797,851$ & $15,668,995$ & 12.14 & & & & & \\
\hline & \multirow{3}{*}{23} & \multirow{3}{*}{ QPAL-Lu7.3 } & \multirow{3}{*}{7} & \multirow{3}{*}{624,461} & \multirow{3}{*}{$5,423,691$} & \multirow{3}{*}{17.74} & \multirow{3}{*}{$\begin{array}{l}\text { QPal.BM.crc-LG7 }{ }^{\mathrm{a}} \\
\text { QPAL.crc-LG9 } \mathrm{b} \\
\text { c79-s540_Lu2534 }\end{array}$} & Lus10001814 & 79,471 & KAS Ic-1 [51] & 3-ketoacyl-acyl carrier protein synthase I \\
\hline & & & & & & & & Lus10028925 & $1,085,389$ & KAS IIIb-2 [51] & 3-ketoacyl-acyl carrier protein synthase III \\
\hline & & & & & & & & Lus10028885 & $1,262,079$ & SUN1 [50] & SAD1/UNC-84 domain protein 1 \\
\hline & 24 & QPAL-Lu11.4 & 11 & $4,417,685$ & $4,429,424$ & & & Lus10026345 & $4,333,672$ & KCS7-1 [51] & 3-ketoacyl-CoA synthase \\
\hline \multirow{3}{*}{ OLE } & \multirow{3}{*}{25} & \multirow{3}{*}{ QOLE-LU8.1 } & \multirow{3}{*}{8} & \multirow{3}{*}{$21,782,841$} & \multirow{3}{*}{$23,527,563$} & \multirow{3}{*}{12.64} & & Lus10006636 & $22,165,534$ & KCS9-1 [51] & 3-ketoacyl-CoA synthase \\
\hline & & & & & & & & Lus10006637 & $22,174,324$ & KCS1-1 [51] & 3-ketoacyl-CoA synthase \\
\hline & & & & & & & & Lus10018485 & $23,111,453$ & DES-1-LIKE [50] & Fatty acid desaturase family protein \\
\hline \multirow{3}{*}{ STE } & 26 & QSTE-Lu9.1 & 9 & $4,229,230$ & $4,229,230$ & & & Lus10040333 & $4,275,842$ & KCS18-2 [51] & 3-ketoacyl-CoA synthase \\
\hline & \multirow{2}{*}{27} & \multirow{2}{*}{ QSTE-Lu9.2 } & 9 & $20,080,531$ & $21,636,823$ & 27.55 & & Lus10011877 & $20,059,127$ & SAD1 [51] & Stearoyl acyl carrier protein desaturase \\
\hline & & & & & & & & Lus10011839 & $20,227,416$ & FatA2-2 [51] & FatA acyl-ACP thioesterase \\
\hline & 28 & QLIO-Lu4.1 & 4 & $19,909,467$ & $19,909,467$ & & & Lus10039906 & $19,833,852$ & KCS14-2 [51] & 3-ketoacyl-CoA synthase \\
\hline LIO & 29 & QLIO-LuT.2 & 7 & $14,540,706$ & $17,977,459$ & 45.70 & $\begin{array}{c}\text { QLIO.crc-LG7 }{ }^{\mathrm{b}} \\
\text { c281-s185_Lu566 }{ }^{\mathrm{C}}\end{array}$ & Lus10038321 & $16,089,922$ & FAD3a [52] & Fatty acid desaturase \\
\hline & 30 & QLIO-Lu12.3 & 12 & 489,561 & $2,981,642$ & 106.22 & $\begin{array}{l}\text { QLIO.crc-LG16 }{ }^{\mathrm{b}} \\
\text { Llio-LG12.3 }^{\mathrm{c}}\end{array}$ & Lus10036184 & $1,035,336$ & $F A D 3 b[52]$ & Fatty acid desaturase \\
\hline & 31 & QLIN-Lu4.1 & 4 & $19,909,467$ & $19,909,467$ & & & Lus10039906 & $19,833,852$ & KCS14-2 [51] & 3-ketoacyl-CoA synthase \\
\hline LIN & 32 & QLIN-LuT.2 & 7 & $14,540,719$ & $17,977,459$ & 45.70 & $\begin{array}{c}\text { QLIN.crc-LG7 }{ }^{\mathrm{b}} \\
\text { c281-s185_Lu566 }\end{array}$ & Lus10038321 & $16,089,922$ & $F A D 3 a[52]$ & Fatty acid desaturase \\
\hline & 33 & QLIN-Lu12.3 & 12 & 489,561 & $2,981,642$ & 106.22 & QLIN.crc-LG16 $^{\mathrm{b}}$ & Lus10036184 & $1,035,336$ & $F A D 3 b[52]$ & Fatty acid desaturase \\
\hline & & & & & & & Llin-LG12.3 ${ }^{\mathrm{c}}$ & Lus10023359 & $1,729,292$ & FAH1 [50] & Fatty acid hydroxylase 1 \\
\hline
\end{tabular}

${ }^{\mathrm{a}}$ QTL identified in [8]; ${ }^{\mathrm{b}}$ QTL identified in [7]; ${ }^{\mathrm{c}}$ QTL identified in [53]. All candidate genes are labelled by references. 

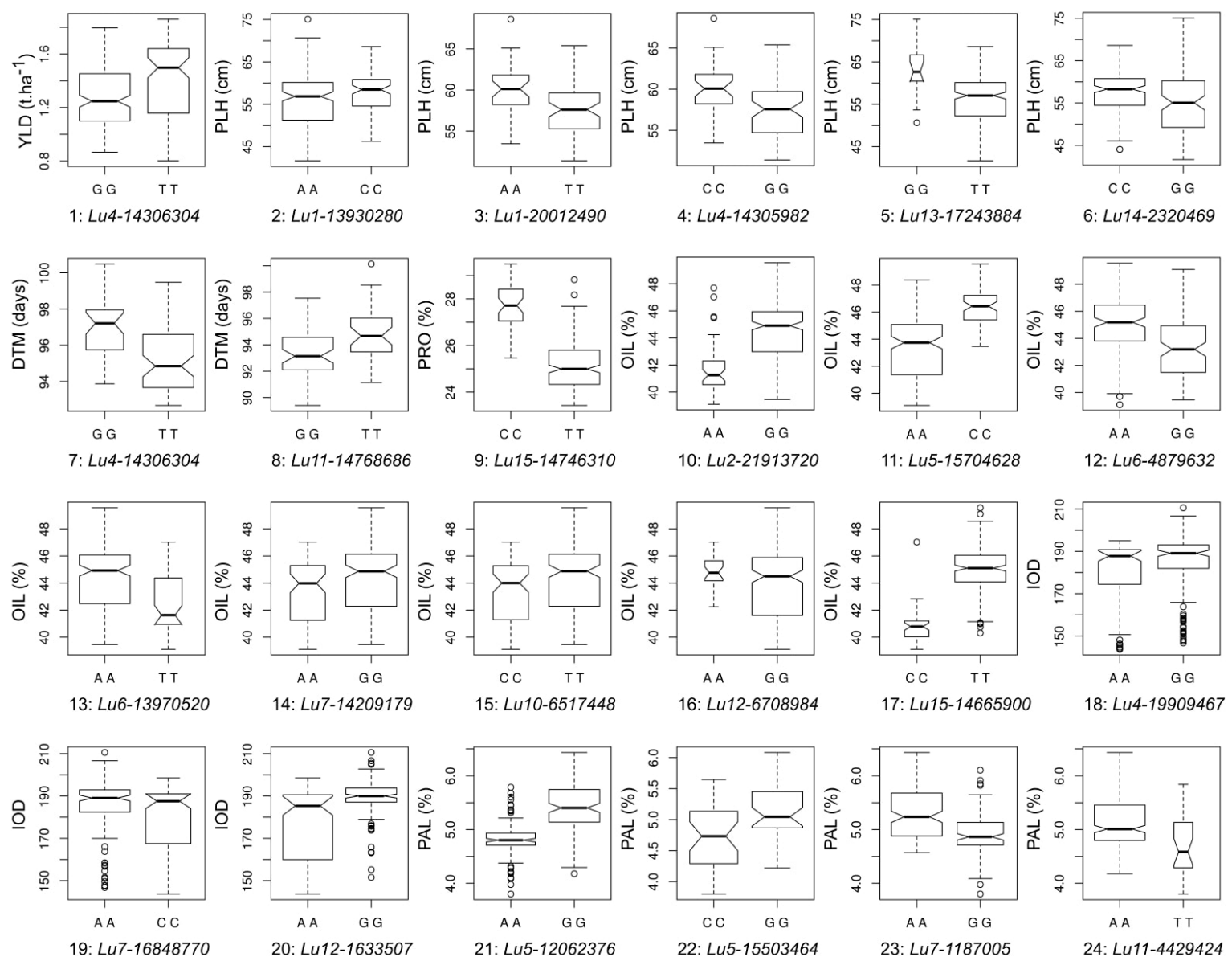

19: Lu7-16848770 20: Lu12-1633507

22: Lu5-15503464

23: Lu7-1187005 24: Lu11-4429424
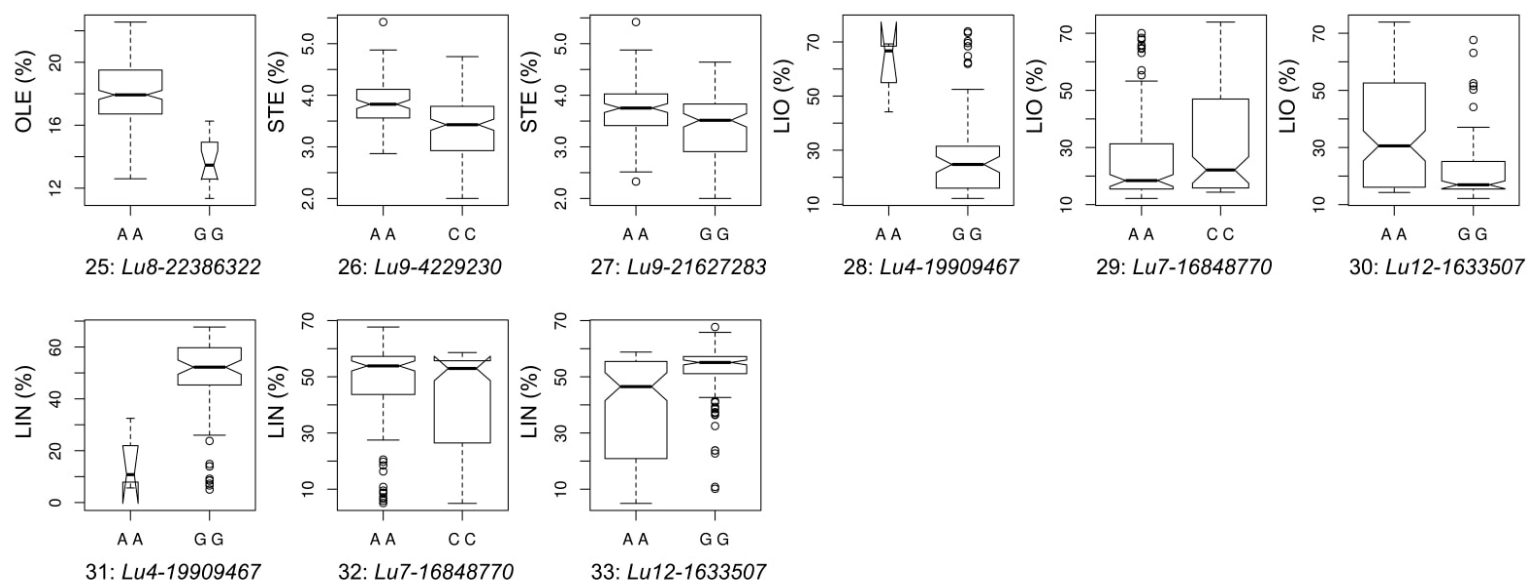

Figure 4. Trait performance of two contrasting haplotype pairs for each of 33 QTL identified from 11 traits. A QTL is represented by the peak SNP identified in the association study. The numbers of QTL correspond to QTL No in Table 3. The BLUP values of the 11 traits in the merged population were used except for PLH/QTL 3 and DTM/QTL 7 for which BM population was used, DTM/QTL 8 for which EV population was used, and PAL/QTL 22, LIO/QTL 28 and LIN/QTL 31 for which SU population was used. The box width is proportional to the size of the subpopulations. Phenotype differences between two contrasting haplotype pairs for each QTL are shown by boxes' notches. For any given QTL, boxes' notches that do not overlap indicate significant median differences at $95 \%$ confidence level. 

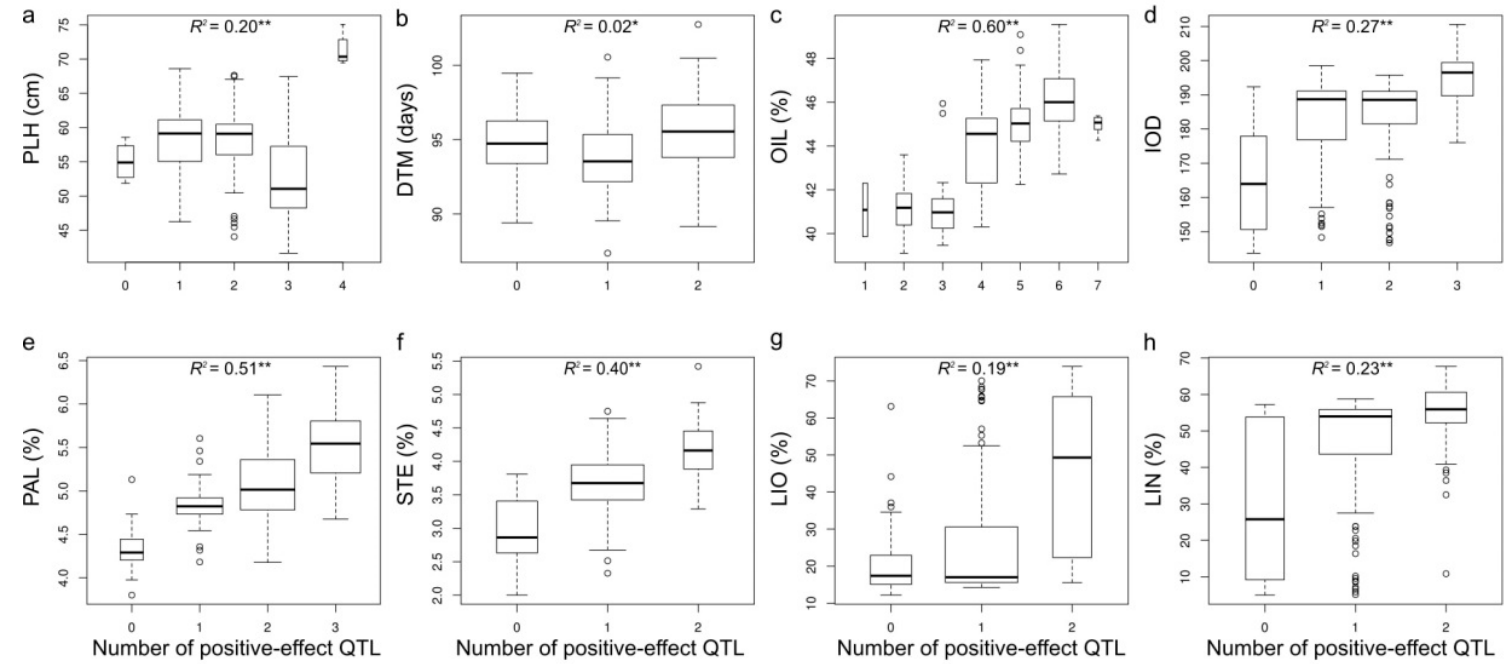

Figure 5. The relationship of phenotypes with the number of positive-effect QTL in individuals. Eight traits with two or more QTL identified were analyzed: (a) plant height (PLH), (b) days to maturity (DTM), (c) oil content (OIL), (d) iodine value (IOD), (e) palmitic acid content (PAL), (f) steric acid content (STE), (g) linoleic acid content (LIO), and (h) linolenic acid content (LIN). The BLUP values of the eight traits in the merged population were used. The correlation of phenotypes with the number of positive-effect QTL was calculated. * and ** represent statistical significance at 0.05 and 0.01 probability level.

\subsection{Pleiotropy of $Q T L$}

Sixteen of the 33 QTL co-located at six genomic regions concerning nine traits (Figures 1 and 6, Table S8). QTL for PLH, DTH and YLD co-located on chr4. QTL for IOD, LIO and LIN co-located on chr4, 7 and 12. Chromosome 15 harbored QTL for OIL and PRO while chr5 had QTL for OIL and PAL.

\subsection{Phenotypic Variation Explained by QTL}

Phenotypic variations explained by individual QTL $\left(h_{\mathrm{QTL}}^{2}\right)$ were estimated (Table S4). Overall, the QTL explained 4 to $66 \%$ of the total phenotypic variation, with an average of $32.5 \%$ which is more than half of the average $h_{S N P}^{2}(51 \%)$. For five traits (IOD, LIO, LIN, PAL and OIL), QTL explained an average of $61 \%$ of the variation (Table 2 and Table S4). We also estimated the phenotypic variation explained by all QTL for a trait $\left(h_{\text {GWAS }}^{2}\right)$ (Table 2). In the merged population, the QTL explained $48-73 \%$ of the phenotypic variation for OIL, IOD, PAL, LIO and LIN but only $8-14 \%$ for PLH, DTM and YLD.

\subsection{Candidate Genes Underlying QTL}

Based on the GWAS results, we investigated the genes annotated in the flax genome [54] in an attempt to predict candidate genes from loci significantly associated with each trait. The genomic locations of SNP markers at the peaks of the QTL were scanned within a $500 \mathrm{~Kb}$ window in either direction to constitute a subset of genes from which we deduced a candidate gene list based on a priori knowledge of their function(s). Candidate genes were identified for every QTL except for the YLD QTL (Table 3). We discovered seven candidate genes underlying QTL for DTM on chr4. The QTL for PLH harbors five candidate genes of completely different function. The genes underlying QTL for fatty acid composition include KCS14-2, FAD3a, and FAD3b for IOD/LIN/LIO, KCS12-3 and KAS Ic-1 for PAL, KCS9-1 and KCS1-1 for OLE, and KCS18-2 and SAD1 for STE. 

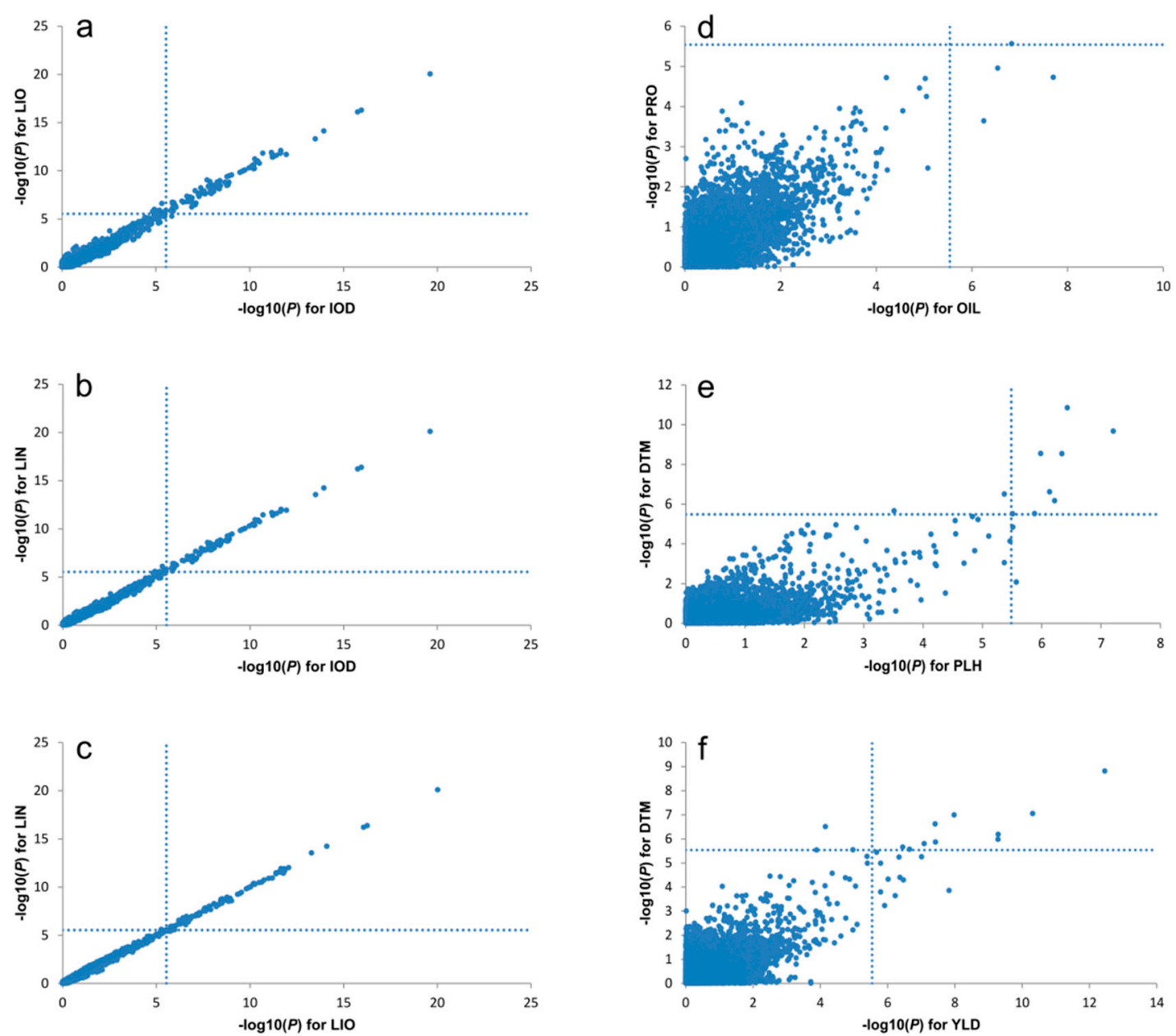

Figure 6. Relations of $-\log _{10}(P)$ values of SNP markers between two traits showing pleiotropy or linkage relationship of SNP markers in different pairs of traits. (a) IOD vs. LIN; (b) IOD vs. LIO; (c) LIN vs. LIO; (d) OIL vs. PRO; (e) PLH vs. DTM; (f) DTM vs. YLD. Results of the GWAS using a GLM and data from the BM + EV + SU population for IOD, LIO, and LIN (a-c), the EV population for OIL and PRO (d), the BM population for PLH and DTM (e) and the BM + EV + SU population for DTM and YLD (f) are shown. The vertical and horizontal dashed lines show the cut-off value of significant SNP markers associated with a trait. YLD: seed yield ( $\left.\mathrm{t} \mathrm{ha}^{-1}\right)$; DTM: days to maturity; OIL: oil content (\%); PRO: protein content (\%); IOD: iodine value; LIO: linoleic acid content (\%); LIN: linolenic acid content $(\%)$.

\subsection{Selection Signatures in Bi-Parental Populations}

A GW3S was performed to identify potential selection signatures during breeding improvement using XP-CLR [34]. Due to the high genetic diversity in BM and EV (Table 1) and large phenotypic differences between them (Table S9), GW3S between BM and EV was conducted. A total of 114 selection signatures with an average size of $226.3 \mathrm{~kb}$ were identified (Figures 1 and 7, Table S10), accounting for $7.82 \%$ of the flax pseudomolecules $(\sim 316 \mathrm{Mb})$. These putative selection signatures overlapped with 11 GWAS-detected genomic regions associated with 18 QTL (Figures 1 and 7). 


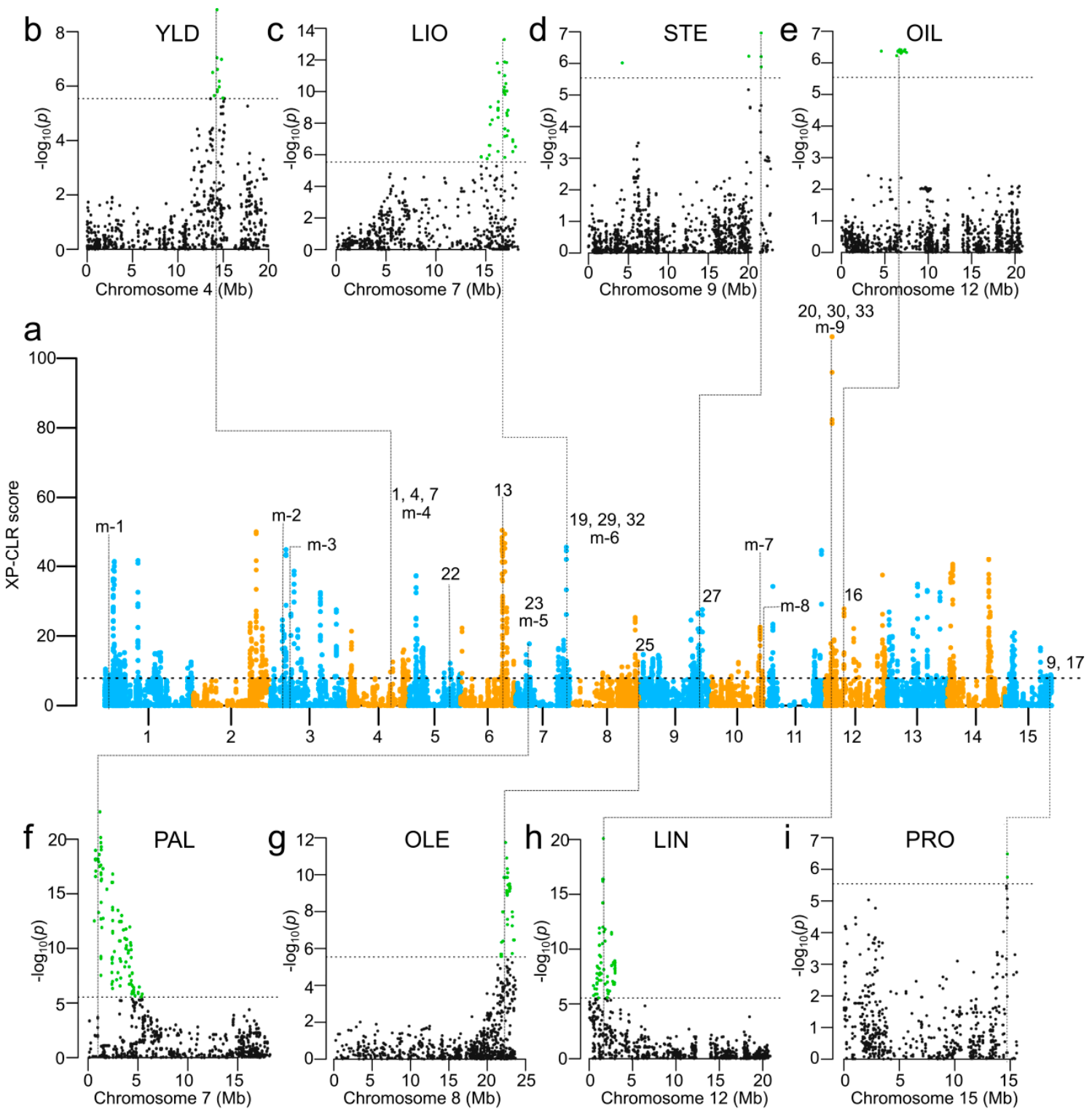

Figure 7. Genome-wide selective sweep scan using XP-CLR between BM and EV (a), and Manhattan plots of QTL overlapping with selective sweeps for (b) seed yield (YLD), (c) linoleic acid content (LIO), (d) steric acid content (STE), (e) oil content (OIL), (f) palmitic acid content (PAL), (g) oleic acid content (OLE), (h) linolenic acid content (LIN), and (i) protein content (PRO). QTL associated with selective sweeps are also labeled on peaks of selective sweeps. The numbers represent the QTL numbers listed in Table 3. Multiple numbers on the same peak represent genomic regions co-located with more than one trait. The labels ' $m$-\#' represent the genomic regions associated with QTL previously identified and listed in Table S11. The green dots on Manhattan plots represent significant SNPs.

Some selection signatures were also associated with previously identified QTL (Table S11). For example, the selection signatures were associated with 10 previously reported QTL (Figure 7). The signatures at position 2.45-2.46 Mb on chr1 overlapped with SNP marker Lu1_2670961 linked to QTL QSte.BM.crc-LG1 for STE; the ones at 4.74-4.77 Mb on chr3 overlapped with Lu3_5950394, a SNP linked to QTL QOle.BM.crc-LG3-1/QLio.BM.crc-LG3 for OLE and LIO; signatures at 7.24-7.25 Mb on chr3 overlapped with SNP Lu3_8415336 linked to QTL QSte.BM.crc-LG3 for STE [8]; position 16.80-16.81 Mb on chr10 harbors signatures that overlap with SSR Lu2262 linked to an unnamed QTL for OIL; finally, position $17.52-17.53 \mathrm{Mb}$ on chr10 has selection signatures that coincide with SSR Lu2746 linked to an unnamed QTL for LIN/IOD [53]. 


\section{Discussion}

\subsection{QTL Associated with Seed Yield and Seed Oil Quality Traits}

Thirty-three QTL were identified in the current study. Of which, nine QTL were identified in previous studies [7,8] for the same traits, including seed yield and seed oil quality traits. Cloutier et al. [7] detected six major QTL for LIO, LIN and IOD in SU population. These six QTL correspond to the two underlying genes, FAD3a and FAD3b. Some of these QTL were in close proximity on the same chromosome. We identified the same QTL by association mapping that were previously detected by linkage mapping [7] using the same phenotype and SNP genotype data in the SU population (Table 3). The refinement of flax pseudomolecule [45] between the linkage study and our current association study allowed reassignment of chr12 for LIO, LIN and IOD QTL which were previously assigned to LG16 [8]. In addition, the same QTL were also detected in the EV population as well as the merged population. Our association study also validated three QTL for YLD, DTM and PAL which were previously identified using linkage mapping using SSRs and SNPs [8,9] and from the association mapping using a flax core collection population with SSR markers [53] (Table 3). These verified QTL for fatty acid composition, seed yield and maturity demonstrate the feasibility of the association mapping method to detect QTL in a bi-parental population as well as a multi-parent population.

An additional 24 novel QTL were detected in our current study which were not discovered in previous studies using individual BM or SU populations. These new QTL were detected using the merged population which greatly increased the population size, thereby enhancing the association power and resolution for QTL detection. We noted that only two QTL were discovered from the BM population alone. This is likely the result of significantly reduced representation of lines re-sequenced from BM population [8]. The discovery of new QTL demonstrates that GWAS using multiple bi-parental populations is equally or more efficient for QTL detection than QTL mapping using single bi-parental populations alone.

We tested the statistical significance of QTL effects for all 33 QTL identified for the 11 traits and found that all effect differences were significant. We also observed significant positive correlation between the number of positive-effect QTL and corresponding trait phenotypes in individuals for eight traits from which had two or more QTL were identified (Figures 4 and 5, Table S7). These results not only corroborate the significance of the QTL but also demonstrate that effects of QTL in an individual performed additively, suggesting that marker-assisted selection (MAS) for these QTL would be effective in breeding. Thus, we listed the flanking sequences of these QTL in Table S12 for MAS purpose.

\subsection{Pleotropic QTL Associated with Seed Yield and Quality Traits}

Six genomic regions associated with more than one trait were identified. QTL for IOD, LIO, and LIN were concurrent on chromosomes 4, 7 and 12; QTL for YLD, PLH, and DTM co-located on chr4; QTL for PRO and OIL were on chr15 and QTL for PAL and OIL were on chr5 (Figures 1 and 6, Table S8).

IOD is a measure of the degree of unsaturation of the oil that is calculated from the GC-derived fatty acid composition. Thus, breeding lines with high LIN normally show high IOD [7] due to the high correlation between IOD, LIO, and LIN [44] (Table S13). QTL co-located at the same genomic regions indicate that the traits may be controlled by the same gene or tightly linked genes. The two genomic regions on chromosomes 7 and 12 harbor the two fatty acid desaturase genes, FAD $3 a$ and $F A D 3 b$. These genes are responsible for linoleic and linolenic acid composition [52,55].

PLH and DTM are complex traits that considerably impact the adaptability, biomass, and economic yield of agricultural crops [56,57]. In soybean, one QTL that strongly associated with both PLH and DTM traits was identified with an SNP at $45.0 \mathrm{Mb}$ position on chromosome 19 and it harbors the candidate gene DT1, which is homolog to Arabidopsis terminal flower 1 (TFL-1, AT5G03840) [56]. Based on in silico gene annotation, the DT1 homolog are located on chromosomes 6 and 8 in flax 
but no QTL for either PLH or DTM were identified on these two chromosomes. This could be due to the lack of functional polymorphism(s) at those loci among the parents of our three populations. However, a different genomic region on chr4 harbours five candidate genes for PLH and seven for DTM, raising the possibility that PLH and DTM are controlled by tightly linked genes in flax. The same genomic region was also associated with YLD. Because plant height and maturity affect seed yield, it is not surprising that QTL for PLH, DTM and YLD were mapped to the same locus. This pleiotropic relationship between YLD and DTM was previously validated [8] (Table 3).

Inheritance of seed oil content is complicated due to its quantitative nature. The seed oil content was directly affected by fatty acid composition traits, such as PAL, STE, OLE, LIO, and LIN, or indirectly by several major agronomic traits, such as seed yield and protein content [58]. Significant correlations of OIL were observed with PAL $(-0.57 ; p=0)$ and PRO $(-0.70 ; p=0)$ (Table S13). OIL is also usually negatively correlated with PRO in oilseed crops [59]. Of the eight QTL associated with oil content, two co-located with QTL for PAL on chr5 and for PRO on chr15, respectively.

\subsection{Phenotypic Variation Explained by SNPs and QTL}

SNP heritability $\left(h_{S N P}^{2}\right)$ for a trait is the total proportion of phenotypic variance explained by additive contributions from genome-wide SNPs. A method for estimating $h_{S N P}^{2}$ for a complex trait was initially proposed in 2011 [60,61] and implemented in GCTA (Genome-wide Complex Trait Analysis) software [61]. Since then, the method has been applied to many quantitative traits largely in human and animal genetic studies $[62,63]$. The method was also used to estimate phenotypic variance explained by a subset of SNPs selected by $p$-values from GWAS in an independent sample [64]. However the estimate of variance explained by the SNP subsets ascertained by the $p$-values from GWAS in the same sample may be inflated due to positive correlation between true SNP effects and estimation errors (personal communication to the GCTA author, Jian Yang). However, as the GCTA-based heritability estimation method includes the population structure effect in the linear model and also considers heritability estimates to be irrelevant to the number of SNPs used [60,61], the accuracy of estimates should be higher than those obtained simply using the simple multivariate regression adopted in most GWAS of plant traits. In the current study, for the first time we applied this method to estimate $h_{S N P}^{2}$ for 11 agronomic and seed quality traits in three bi-parental populations and a merged population. As the number of SNPs identified from a population depends on its genetic variation for the traits, the trait-associated $h_{S N P}^{2}$ estimates vary across populations and traits. Overall, seed yield had a lower $h_{S N P}^{2}$ than seed quality traits as expected considering the extent of genetic complexity of the former (Table 2). We also used the same method to estimate phenotypic variation explained by individual QTL $\left(h_{Q T L}^{2}\right)$ and by all QTL for a specific trait $\left(h_{G W A S}^{2}\right) . h_{G W A S}^{2}$ measures the extent of the phenotypic variation explained by QTL compared to that of all SNPs. This comparison led to the conclusion that many QTL for PLH, DTM and YLD were not detected in our study but the QTL for seed quality traits identified herein likely represent major genetic regions or genes controlling these traits.

\subsection{Selection Signatures Associated with Seed Yield and Seed Quality Traits}

GW3S has been used for screening putative genomic regions under selection pressure caused by domestication or artificial selection $[36,38]$. Usually, contrasting genetic populations are compared (such as wild accessions vs. cultivated accessions, landraces vs. breeding lines) to identify the allele frequency differentiation between different populations. In this study, we alternatively used two contrasting bi-parental mapping populations and identified 114 selection signatures with an average size of $226.3 \mathrm{~kb}$. Some of these selection signatures support nearly $50 \%$ of the 23 GWAS-detected genomic regions associated with 33 QTL. Some of the QTL identified by GWAS have no overlapping selection signatures, partially because the regions of QTL had XP-CLR (Cross Population Composite Likelihood Ratio) scores less than the predetermined cut-off values. On the other hand, many selection signatures have high XP-CLR scores but no associated QTL (Figure 7). These significant selection signatures may be associated with QTL for traits not included in this study. This is suggested by the 
fact that five previously identified genomic regions related to seven QTL overlapped with the selection signatures identified in our current study comparing BM and EV (Table S10). These putative selection signatures provide useful candidates for further QTL-trait association study. Our results combined with previous studies demonstrate that GW3S combined with GWAS is a powerful approach for dissecting genetic structure of breeding populations and for the identification of underlying genomic regions for breeding improvement. Using GWAS with bi-parental populations and selection signatures allowed the cross validation of QTL previously identified by other mapping methods and established the foundation for genomic assisted breeding in flax.

\section{Materials and Methods}

\subsection{Plant Materials}

Three bi-parental mapping populations of different genetic backgrounds served as genotype panel for the association study. The first population (BM) consisted of $243 \mathrm{~F}_{6}$-derived RILs generated by single seed descent from a cross between CDC Bethune and Macbeth. Its two parents are Canadian high-yielding conventional linseed cultivars with 55-57\% LIN $[65,66]$. The second population (EV) contained $90 \mathrm{~F}_{6}$-derived RILs from a cross between E1747, an ethyl methanesulfonate (EMS)-induced low LIN breeding line [67], and Viking, a French fiber flax cultivar with 55\% LIN that was grown extensively in the 2000's but deregistered in 2012. The third population (SU) is an $F_{1}$-derived DH population of 78 lines obtained from a cross between the breeding line SP2047, from which a yellow-seeded Solin ${ }^{\mathrm{TM}} 2047$ with only 2-3\% LIN has been derived, and breeding line UGG5-5, which is a high LIN line with 63-66\% LIN [7,55]. BM was designed to study yield-related traits while EV and SU were intended for QTL identification for fatty acid composition and fiber traits.

\subsection{Whole Genome Resequencing, SNP Calling, SNP Imputation and LD Analysis}

Three populations consisting of 97 randomly selected lines from BM, 91 from EV, 72 from SU including five parents (one parent is the reference genome) were grown in growth cabinets with a 16-h light and 8-h dark cycle at $20 / 18{ }^{\circ} \mathrm{C}$. DNA was extracted from young leaf tissue using the DNeasy 96 Plant kit (Qiagen, Mississauga, ON, Canada) according to the manufacturer's instructions. The DNA was subsequently restricted, size-selected and quantified prior to the construction of the reduced representation libraries used for Illumina sequencing as previously described [47]. Reduced representation libraries from a total of 260 individuals of the three populations, i.e., 96 randomly selected from BM, 89 from EV, 70 from SU, and five parents (One parent CDC Bethune of $\mathrm{BM}$ is used as a reference genome) were re-sequenced by the Michael Smith Genome Sciences Centre of the BC Cancer Agency, Genome British Columbia (Vancouver, BC, Canada) using 100-bp paired-end reads on an Illumina HiSeq 2000 platform (Illumina Inc., San Diego, CA, USA).

SNP calling was performed using the revised AGSNP pipeline $[47,48,68]$. The flax scaffold sequences of cultivar CDC Bethune [46] were used as reference for read mapping. Then SNPs were called using SAMtools [69] and further filtered using a set of criteria such as mapped read depth, consensus base ratio, mapping quality score and homopolymers with a validation rate of $96.8 \%$ for the called SNPs as described in detail [47]. Finally SNPs with a MAF $<0.05$ and a genotyping rate $<60 \%$ were removed for further analysis. The coordinates of all SNPs were extracted from the chromosome-based flax pseudomolecules v2.0 [45]. Missing data for these filtered SNPs were imputed using Beagle v.4.2 [70].

Intra-chromosome LD $\left(r^{2}\right)$ was calculated using plink ver. 1.9 [71] with the parameters "-r2 -ld-window-kb 2000 -ld-window-r2 0". Before LD calculation, SNP data were pruned using the parameter "-indep-pairwise 200050 0.9" to remove SNPs with high $r^{2}(>0.9)$ in a $2000 \mathrm{~kb}$ window with step size of 50 SNPs. Pair-wise $r^{2}$ values were plotted against the base pair distance, and curves 
of LD decay with distances of paired SNPs were fitted using a non-linear regression model [72] as follows:

$$
r^{2}=\frac{10+c d}{(2+c d)(11+c d)} \times\left\{1+\frac{(3+c d)\left(12+12 c d+(c d)^{2}\right)}{n(2+c d)(11+c d)}\right\}
$$

where $c$ is the coefficient to be estimated, $d$ is the distance between pair-wise SNPs, and $n$ is the number of total gametes, corresponding to twice the number of individuals in a population. The R function $n l s$ was used to fit the model. The rate of LD decay for each population was determined from the fitted model at the half of the maximum $\operatorname{LD}\left(r^{2}\right)$. Haplotype blocks were calculated using plink with the parameters "-blocks no-pheno-req-blocks-max-kb 2000".

\subsection{Differentiation and Stratification}

Nucleotide diversity $(\pi)$ of three bi-parental populations and genetic differentiation $\left(F_{s t}\right)$ between the populations were estimated using the R package "PopGenome" [73]. The genetic structures of the three separate inbreeding populations and the combined population were assessed using both PCA and DAPC [74]. Analyses with DAPC included several steps: (1) PCA was conducted using the imputed SNPs. According to the curve of accumulative variances against the number of principle components (PCs), the optimum number of PCs was chosen at which the cumulative variance had no obvious increase; (2) $k$-means clustering analysis was performed based on the chosen PCs. To identify the optimal number of clusters, $k$-means was run sequentially with increasing $k$ values and the Bayesian information criterion (BIC) was calculated for each $k$. The optimum $k$ corresponded to the lowest BIC; (3) Discriminant analysis was conducted based on the chosen clusters and individuals were reassigned to the different clusters. The posterior probability of cluster membership was calculated based on the retained discrimination functions and used as the Q matrix for GWAS and heritability estimation. PCA was performed using the function implemented in TASSEL while DAPC was conducted using the R package "adegenet" 2.0 [75].

\subsection{Phenotyping of Bi-Parental Populations}

Individuals from the three populations were evaluated in field trials over four years (2009-2012) at two sites, Morden Research and Development Centre, Manitoba (MD) and Kernen Crop Research Farm near Saskatoon, Saskatchewan (SAS) in Canada. A type-2 modified augmented design (MAD) [76] was used for the field experiments from which phenotypic data were collected. The detailed experimental design was previously described [44,77]. All 243 individuals of the BM population were phenotyped in four years (2009-2012) and two sites (MD and SAS), while 86 individuals of the EV population and 72 individuals of the SU population were evaluated in three years (2010-2012) and two sites (MD and SAS).

Eleven common traits were evaluated in the three populations, including YLD, PLH, DTM, PRO, OIL, IOD and five fatty acid composition traits (OLE, PAL, STE, LIO, and LIN). PLH was measured from ground to the uppermost part of the plant at maturity. DTM was recorded from sowing to $95 \%$ of capsule maturity (seeds rattling in the capsules or bolls). Seed yield data were measured by harvesting two $0.5-\mathrm{m}$ sections from rows located in the central part of each subplot $\left(0.2 \mathrm{~m}^{2}\right)$. A total of $1 \mathrm{~g}$ of seed from each line at each environment was sampled for OIL measurement and fatty acid composition. Methyl esters of fatty acids were prepared according to the American Oil Chemists' Society (AOCS) Official Method Ce 2-66 [78] and fatty acid composition was measured by gas chromatography (GC) following AOCS Official Method Ce 1e-91. OIL was determined by nuclear magnetic resonance calibrated against the FOSFA extraction reference method. PRO was measured using near-infrared spectroscopy calibrated against the combustion analysis reference method and expressed on an $\mathrm{N} \times 6.25$ dry basis. Phenotyping of these seed quality traits has been previously described [53]. All phenotypic data from the field experiments and laboratory measurements were adjusted for soil heterogeneity as previously described based on the MAD pipeline [77]. The BLUP 
values over multiple environmental phenotypes estimated using R package "lme4" [79] were used for further association study analyses. The Shapiro-Wilk normality test was performed for all traits using the R function "shapiro.test". All 11 traits followed approximately a normal or mixed normal distribution (Figure S3). Simple correlations among 11 traits were calculated using the function "rcorr" of the R package "Hmisc".

\subsection{Phenotypic Variation Explained by All SNPS}

The phenotypic variation explained by all SNPs, denoted as $h_{S N P}^{2}$, was estimated for all traits based on the following mixed linear model [60] implemented in the GCTA software [61]:

$$
\boldsymbol{y}=\boldsymbol{X} \boldsymbol{\beta}+\boldsymbol{g}+\boldsymbol{\varepsilon} \text { with its variance } \boldsymbol{V}=\boldsymbol{A} \sigma_{g}^{2}+\boldsymbol{I} \sigma_{\varepsilon}^{2}
$$

where $y$ is an $n \times 1$ vector of phenotypes with $n$ individuals in a population, $X$ is the $n \times n$.

structure matrix, $\beta$ is a vector of fixed effects of population structure, including posterior probabilities of an individual assigning to a cluster in DAPC, $g$ is an $n \times 1$ vector of the total genetic effects of the individuals with $g \sim N\left(\mathbf{0}, \boldsymbol{A} \sigma_{g}^{2}\right)$, and $\varepsilon$ is a vector of residual effects with $\varepsilon \sim N\left(\mathbf{0}, \mathbf{I} \sigma_{\varepsilon}^{2}\right)$. $\boldsymbol{A}$ is interpreted as the genetic relationship matrix (GRM) between individuals and estimated from SNPs. $\sigma_{g}^{2}$ is estimated using the restricted maximum likelihood (REML) method based on the GRM estimated from all SNPs. Thus, SNP heritability $h_{S N P}^{2}$ was estimated as

$$
h_{S N P}^{2}=\frac{\sigma_{g}^{2}}{\sigma_{g}^{2}+\sigma_{\varepsilon}^{2}}
$$

\subsection{Genome-Wide Association Study}

GWAS was performed with the GLM and compressed MLM $[80,81]$ implemented in TASSEL (v5.2) [82], which employs the EMMA and P3D algorithms to reduce computing time. For MLM, the kinship matrices for the merged population and the three single populations were calculated using TASSEL (v5.2) [82]. Manhattan plots and quantile-quantile (Q-Q) plots of GWAS were obtained using the R package "qqman" [83].

SNP markers for candidate QTL were determined based on the $p$-value for each marker estimated in the GLM or MLM analysis. The $p$-values were adjusted by the Bonferroni correction, being $\alpha$ (0.05)/No. of SNPs used in the analyses. Allele effects of significant markers were calculated as the difference between the average phenotypic values of homozygous alleles which were obtained directly from the TASSEL outputs. Candidate QTL were defined based on peaks of SNPs exceeded the significance threshold for the trait. The genomic region for a QTL was defined as a genome block spanning all significant SNPs.

The amount of phenotypic variation explained by significant QTL was estimated for all SNP markers within the QTL regions using the same method as described above [61], denoted as $h_{\text {QTL }}^{2}$. We similarly estimated phenotypic variation explained by all significant QTL for a single trait and denoted it $h_{G W A S}^{2}$.

\subsection{Candidate Gene Mining}

Genome-wide gene scan along chromosomes for significant QTL was performed to characterize the underlying genomic regions and identify candidate genes. First, all orthologous genes of the model species Arabidopsis thaliana were mapped to the flax genome using BLASTP of flax protein sequences against $A$. thaliana protein sequences at an E-value of $1.0 \times 10^{-10}$. A total of 15,323 unique $A$. thaliana genes were mapped. A list of known flax or $A$. thaliana genes associated with our studied traits and their associations was drawn based on literature and database searches $[49,51,84]$. We investigated candidate genes within QTL regions or within a $500 \mathrm{~kb}$ window upstream and downstream of the 
peaks depending on the LD decay estimates. In addition, previously identified QTL (SSR markers) in flax $[7,8,53]$ were mapped to the flax pseudomolecules to validate the QTL results from this study.

\subsection{QTL Validation}

Three approaches were applied to validate QTL identified by GWAS. The first approach was to compare our QTL with previously identified QTL as described above. The same QTL was inferred if two QTL were mapped to the same recombination block or haplotype block. The second approach tested the significance of difference of phenotypes between two contrasting haplotype pairs of a QTL in the populations. Statistically significant differences served to validate significant QTL. Both $t$ and Wilcox non-parametric tests were performed using the R functions "t.test" and "wilcox.test" for each QTL in the merged and individual populations and in different year/location environments. To test the positive correlations of a trait upon pyramiding of QTL, a simple regression of the number of positive-effect QTL on phenotypic values of a trait was calculated. A positive-effect QTL in an individual meant that this individual possessed a positive effect allele for the QTL. The last approach was to perform genome-wide selective sweep scans to confirm QTL associated genomic regions as described below.

\subsection{Genome-Wide Selective Sweep Scan}

A WG3S was performed along chromosomes across two populations using the program XP-CLR [34]. Comparisons between BM and EV using XP-CLR were conducted. The genetic distances (cM) between SNPs were estimated using the integrated flax consensus genetic map [43], assuming uniform recombination between SNPs. For each chromosome, XP-CLR was executed with the parameters "-w1 0.0051001001 -p1 0.7" to estimate XP-CLR scores for 100-bp windows. Each chromosome was then divided into 10-kb segments and the highest XP-CLR score from windows with at least one SNP were assigned to each 10-kb segment $\left(x_{\max , i}\right)$. If the XP-CLR scores $\left(x_{\max , i}\right.$ and $\left.x_{\max , i+1}\right)$ of two adjacent $10-\mathrm{kb}$ segments were greater than the 80 th percentile $\left(x_{\max , 80 t h}\right)$ of the genome-wide scores of all 10-kb fragments, then they were grouped as a single putative selective sweep. In addition, putative selective sweeps were also merged if they were separated by no more than one low score $\left(<x_{\max }, 80 t h\right)$ segment. Merged selective sweeps were assigned the highest score from their merged 10-kb segments. These merged segments were further combined into a larger region if these segments belonged to the same peak in the genome-wide selective sweep plot (Figure 5a). Finally, the combined regions falling in the highest 10th percentile of all putative selective sweeps were considered differentially selected regions or selection signatures.

The selection signatures were compared to both our detected QTL and previously reported QTL on the genetic loci to find associations between them. Positions where the QTL corresponding markers were located were extended by $100 \mathrm{~kb}$ on both sides and then compared with the position of the selection signatures. The QTL and selection signatures were considered associated when they overlapped.

Supplementary Materials: Supplementary materials can be found at http:/ / www.mdpi.com/1422-0067/19/8/ 2303/s1.

Author Contributions: S.C., F.M.Y., S.D.D., H.M.B. and K.Y.R. conceived and designed the study. S.C. performed sequencing. S.D.D., H.M.B. and K.Y.R. performed the phenotyping. F.M.Y., J.X., P.L., Z.Y., G.J., L.H., S.K. and B.S.-C. analyzed the data. F.M.Y., J.X., S.K. and S.C. wrote the manuscript. All authors reviewed and edited the manuscript.

Funding: This research was funded by Genome Canada and other industrial stakeholders for the Total Utilization Flax GENomics (TUFGEN) project, by Agriculture and Agri-Food Canada for an A-base project, and by Western Grain Research Foundation (WGRF) and the Saskatchewan Flax Development Commission (SFDC) for the flax breeding database project.

Conflicts of Interest: The authors declare no conflict of interest. The funders had no role in the design of the study; in the collection, analyses, or interpretation of data; in the writing of the manuscript, and in the decision to publish the results. 


\section{Abbreviations}

$\begin{array}{ll}\text { DH } & \text { doubled haploid } \\ \text { GBS } & \text { genotyping by sequencing } \\ \text { GW3S } & \text { genome-wide selective sweep scan } \\ \text { GWAS } & \text { genome-wide association study } \\ \text { IOD } & \text { iodine value } \\ \text { LD } & \text { linkage disequilibrium } \\ \text { LIN } & \text { linolenic acid } \\ \text { LIO } & \text { linoleic acid } \\ \text { MAF } & \text { minor allele frequency } \\ \text { MAGIC } & \text { multi-parent advanced generation intercross } \\ \text { NAM } & \text { nested association mapping } \\ \text { OIL } & \text { oil content } \\ \text { OLE } & \text { oleic acid } \\ \text { PAL } & \text { palmitic acid } \\ \text { QTL } & \text { quantitative trait loci } \\ \text { RIL } & \text { recombinant inbred line } \\ \text { SNP } & \text { single nucleotide polymorphism } \\ \text { SSR } & \text { simple sequence repeat } \\ \text { STE } & \text { stearic acid } \\ \text { YLD } & \text { seed yield }\end{array}$

\section{References}

1. Westcott, N.D.; Muir, A.D. Chemical studies on the constituents of Linum spp. In Flax, the Genus Linum; Muir, A.D., Westcott, N.D., Eds.; Taylor and Francis: New York, NY, USA, 2003; pp. 55-73.

2. Diederichsen, A.; Kusters, P.M.; Kessler, D.; Bainas, Z.; Gugel, R.K. Assembling a core collection from the flax world collection maintained by Plant Gene resources of Canada. Genet. Resour. Crop Evol. 2013, 60, 1479-1485. [CrossRef]

3. Green, A.G.; Chen, Y.; Singh, S.P.; Dribnenki, J.C.P. Flax. In Compendium Transgenic Crop Plants: Transgenic Oilseed Crops; Kole, C., Hall, T.C., Eds.; Blackwell Publishing Ltd.: Oxford, UK, 2008; pp. 199-226.

4. Tolkachev, O.N.; Zhuchenko, A.A. Biologically active substances of flax: Medicinal and nutritional properties. Pharm. Chem. J. 2000, 34, 360-367. [CrossRef]

5. You, F.M.; Duguid, S.D.; Lam, I.; Cloutier, S.; Rashid, K.Y.; Booker, H. Pedigrees and genetic base of the flax varieties registered in Canada. Can. J. Plant Sci. 2016, 96, 837-852. [CrossRef]

6. Price, A.H. Believe it or not, QTLs are accurate! Trends Plant Sci. 2006, 11, 213-216. [CrossRef] [PubMed]

7. Cloutier, S.; Ragupathy, R.; Niu, Z.; Duguid, S.D. SSR-based linkage map of flax (Linum usitatissimum L.) and mapping of QTLs underlying fatty acid composition traits. Mol. Breed. 2011, 28, 437-451. [CrossRef]

8. Kumar, S.; You, F.M.; Duguid, S.; Booker, H.; Rowland, G.; Cloutier, S. QTL for fatty acid composition and yield in linseed (Linum usitatissimum L.). Theor. Appl. Genet. 2015, 128, 965-984. [CrossRef] [PubMed]

9. Asgarinia, P.; Cloutier, S.; Duguid, S.; Rashid, K.; Mirlohi, A.; Banik, M.; Saeidi, G. Mapping quantitative trait loci for powdery mildew resistance in flax (Linum usitatissimum L.). Crop Sci. 2013, 53, 2462-2472. [CrossRef]

10. Fu, Y.-B. Genetic evidence for early flax domestication with capsular dehiscence. Genet. Resour. Crop Evol. 2011, 58, 1119-1128. [CrossRef]

11. Soto-Cerda, B.J.; Maureira-Butler, I.; Muñoz, G.; Rupayan, A.; Cloutier, S. SSR-based population structure, molecular diversity and linkage disequilibrium analysis of a collection of flax (Linum usitatissimum L.) varying for mucilage seed-coat content. Mol. Breed. 2012, 30, 875-888. [CrossRef]

12. Wiesnerova, D.; Wiesner, I. ISSR-based clustering of cultivated flax germplasm is statistically correlated to thousand seed mass. Mol. Biotechnol. 2004, 26, 207-213. [CrossRef]

13. McMullen, M.D.; Kresovich, S.; Villeda, H.S.; Bradbury, P.; Li, H.; Sun, Q.; Flint-Garcia, S.; Thornsberry, J.; Acharya, C.; Bottoms, C. Genetic properties of the maize nested association mapping population. Science 2009, 325, 737-740. [CrossRef] [PubMed] 
14. Bandillo, N.; Raghavan, C.; Muyco, P.A.; Sevilla, M.A.L.; Lobina, I.T.; Dilla-Ermita, C.J.; Tung, C.-W.; McCouch, S.; Thomson, M.; Mauleon, R.; et al. Multi-parent advanced generation inter-cross (MAGIC) populations in rice: Progress and potential for genetics research and breeding. Rice 2013, 6, 11. [CrossRef] [PubMed]

15. Yu, J.; Holland, J.B.; McMullen, M.D.; Buckler, E.S. Genetic design and statistical power of nested association mapping in maize. Genetics 2008, 178, 539-551. [CrossRef] [PubMed]

16. Monir, M.M.; Zhu, J. Dominance and epistasis interactions revealed as important variants for leaf traits of maize NAM population. Front. Plant Sci. 2018, 9, 627. [CrossRef] [PubMed]

17. Ren, D.; Fang, X.; Jiang, P.; Zhang, G.; Hu, J.; Wang, X.; Meng, Q.; Cui, W.; Lan, S.; Ma, X.; et al. Genetic architecture of nitrogen-deficiency tolerance in wheat seedlings based on a nested association mapping (NAM) population. Front. Plant Sci. 2018, 9, 845. [CrossRef] [PubMed]

18. Mackay, I.; Powell, W. Methods for linkage disequilibrium mapping in crops. Trends Plant Sci. 2007, 12, 57-63. [CrossRef] [PubMed]

19. Cavanagh, C.; Morell, M.; Mackay, I.; Powell, W. From mutations to MAGIC: Resources for gene discovery, validation and delivery in crop plants. Curr. Opin. Plant Biol. 2008, 11, 215-221. [CrossRef] [PubMed]

20. Mathew, B.; Leon, J.; Sannemann, W.; Sillanpaa, M.J. Detection of epistasis for flowering time using Bayesian multilocus estimation in a barley MAGIC population. Genetics 2018, 208, 525-536. [CrossRef] [PubMed]

21. Camargo, A.V.; Mackay, I.; Mott, R.; Han, J.; Doonan, J.H.; Askew, K.; Corke, F.; Williams, K.; Bentley, A.R. Functional mapping of quantitative trait loci (QTLs) associated with plant performance in a wheat magic mapping population. Front. Plant Sci. 2018, 9, 887. [CrossRef] [PubMed]

22. Ongom, P.O.; Ejeta, G. Mating design and genetic structure of a multi-parent advanced generation intercross (magic) population of sorghum (Sorghum bicolor (L.) Moench). G3 (Bethesda) 2018, 8, 331-341. [CrossRef] [PubMed]

23. Huynh, B.L.; Ehlers, J.D.; Huang, B.E.; Munoz-Amatriain, M.; Lonardi, S.; Santos, J.R.P.; Ndeve, A.; Batieno, B.J.; Boukar, O.; Cisse, N.; et al. A multi-parent advanced generation inter-cross (MAGIC) population for genetic analysis and improvement of cowpea (Vigna unguiculata L. Walp.). Plant J. 2018, 93, 1129-1142. [CrossRef] [PubMed]

24. Ponce, K.S.; Ye, G.; Zhao, X. Qtl identification for cooking and eating quality in indica rice using multi-parent advanced generation intercross (MAGIC) population. Front. Plant Sci. 2018, 9, 868. [CrossRef] [PubMed]

25. Huang, C.; Shen, C.; Wen, T.; Gao, B.; Zhu, D.; Li, X.; Ahmed, M.M.; Li, D.; Lin, Z. SSR-based association mapping of fiber quality in upland cotton using an eight-way MAGIC population. Mol. Genet. Genom. 2018, 293, 793-805. [CrossRef] [PubMed]

26. Garrido-Cardenas, J.A.; Mesa-Valle, C.; Manzano-Agugliaro, F. Trends in plant research using molecular markers. Planta 2018, 247, 543-557. [CrossRef] [PubMed]

27. Pena, R.N.; Ros-Freixedes, R.; Tor, M.; Estany, J. Genetic marker discovery in complex traits: A field example on fat content and composition in pigs. Int. J. Mol. Sci. 2016, 17. [CrossRef] [PubMed]

28. Zhu, X.M.; Shao, X.Y.; Pei, Y.H.; Guo, X.M.; Li, J.; Song, X.Y.; Zhao, M.A. Genetic diversity and genome-wide association study of major ear quantitative traits using high-density SNPs in maize. Front. Plant Sci. 2018, 9, 966. [CrossRef] [PubMed]

29. Chen, L.; Wan, H.; Qian, J.; Guo, J.; Sun, C.; Wen, J.; Yi, B.; Ma, C.; Tu, J.; Song, L.; et al. Genome-wide association study of cadmium accumulation at the seedling stage in rapeseed (Brassica napus L.). Front. Plant Sci. 2018, 9, 375. [CrossRef] [PubMed]

30. MacGregor, S.; Ong, J.S.; An, J.; Han, X.; Zhou, T.; Siggs, O.M.; Law, M.H.; Souzeau, E.; Sharma, S.; Lynn, D.J.; et al. Genome-wide association study of intraocular pressure uncovers new pathways to glaucoma. Nat. Genet. 2018, 50, 1067-1071. [CrossRef] [PubMed]

31. Huang, X.; Wei, X.; Sang, T.; Zhao, Q.; Feng, Q.; Zhao, Y.; Li, C.; Zhu, C.; Lu, T.; Zhang, Z.; et al. Genome-wide association studies of 14 agronomic traits in rice landraces. Nat. Genet. 2010, 42, 961-967. [CrossRef] [PubMed]

32. Meng, L.; Zhao, X.; Ponce, K.; Ye, G.; Leung, H. QTL mapping for agronomic traits using multi-parent advanced generation inter-cross (MAGIC) populations derived from diverse elite indica rice lines. Field Crops Res. 2016, 189, 19-42. [CrossRef]

33. Huang, X.; Han, B. Natural variations and genome-wide association studies in crop plants. Annu. Rev. Plant Biol. 2014, 65, 531-551. [CrossRef] [PubMed] 
34. Chen, H.; Patterson, N.; Reich, D. Population differentiation as a test for selective sweeps. Genome Res. 2010, 20, 393-402. [CrossRef] [PubMed]

35. Gore, M.A.; Chia, J.M.; Elshire, R.J.; Sun, Q.; Ersoz, E.S.; Hurwitz, B.L.; Peiffer, J.A.; McMullen, M.D.; Grills, G.S.; Ross-Ibarra, J.; et al. A first-generation haplotype map of maize. Science 2009, 326, 1115-1117. [CrossRef] [PubMed]

36. Xie, W.; Wang, G.; Yuan, M.; Yao, W.; Lyu, K.; Zhao, H.; Yang, M.; Li, P.; Zhang, X.; Yuan, J.; et al. Breeding signatures of rice improvement revealed by a genomic variation map from a large germplasm collection. Proc. Natl. Acad. Sci. USA 2015, 112, E5411-5419. [CrossRef] [PubMed]

37. Wen, Z.; Boyse, J.F.; Song, Q.; Cregan, P.B.; Wang, D. Genomic consequences of selection and genome-wide association mapping in soybean. BMC Genom. 2015, 16, 671. [CrossRef] [PubMed]

38. Zhou, Z.; Jiang, Y.; Wang, Z.; Gou, Z.; Lyu, J.; Li, W.; Yu, Y.; Shu, L.; Zhao, Y.; Ma, Y.; et al. Resequencing 302 wild and cultivated accessions identifies genes related to domestication and improvement in soybean. Nat. Biotechnol. 2015, 33, 408-414. [CrossRef] [PubMed]

39. He, C.; Fu, J.; Zhang, J.; Li, Y.; Zheng, J.; Zhang, H.; Yang, X.; Wang, J.; Wang, G. A gene-oriented haplotype comparison reveals recently selected genomic regions in temperate and tropical maize germplasm. PLoS ONE 2016, 12, e0169806. [CrossRef] [PubMed]

40. Jordan, K.W.; Wang, S.; Lun, Y.; Gardiner, L.J.; MacLachlan, R.; Hucl, P.; Wiebe, K.; Wong, D.; Forrest, K.L.; Sharpe, A.G.; et al. A haplotype map of allohexaploid wheat reveals distinct patterns of selection on homoeologous genomes. Genome Biol. 2015, 16, 48. [CrossRef] [PubMed]

41. Cadzow, M.; Boocock, J.; Nguyen, H.T.; Wilcox, P.; Merriman, T.R.; Black, M.A. A bioinformatics workflow for detecting signatures of selection in genomic data. Front. Genet. 2014, 5, 293. [CrossRef] [PubMed]

42. Korte, A.; Farlow, A. The advantages and limitations of trait analysis with GWAS: A review. Plant Methods 2013, 9, 29. [CrossRef] [PubMed]

43. Cloutier, S.; Ragupathy, R.; Miranda, E.; Radovanovic, N.; Reimer, E.; Walichnowski, A.; Ward, K.; Rowland, G.; Duguid, S.; Banik, M. Integrated consensus genetic and physical maps of flax (Linum usitatissimum L.). Theor. Appl. Genet. 2012, 125, 1783-1795. [CrossRef] [PubMed]

44. You, F.M.; Booker, M.H.; Duguid, D.S.; Jia, G.; Cloutier, S. Accuracy of genomic selection in biparental populations of flax (Linum usitatissimum L.). Crop J. 2016, 4, 290-303. [CrossRef]

45. You, F.M.; Xiao, J.; Li, P.; Yao, Z.; Jia, G.; He, L.; Zhu, T.; Luo, M.C.; Wang, X.; Deyholos, M.K.; et al. Chromosome-scale pseudomolecules refined by optical, physical and genetic maps in flax. Plant J. 2018, 95, 371-384. [CrossRef] [PubMed]

46. Wang, Z.; Hobson, N.; Galindo, L.; Zhu, S.; Shi, D.; McDill, J.; Yang, L.; Hawkins, S.; Neutelings, G.; Datla, R.; et al. The genome of flax (Linum usitatissimum) assembled de novo from short shotgun sequence reads. Plant J. 2012, 72, 461-473. [CrossRef] [PubMed]

47. Kumar, S.; You, F.M.; Cloutier, S. Genome wide SNP discovery in flax through next generation sequencing of reduced representation libraries. BMC Genom. 2012, 13, 684. [CrossRef] [PubMed]

48. You, F.M.; Deal, K.R.; Wang, J.; Britton, M.T.; Fass, J.N.; Lin, D.; Dandekar, A.M.; Leslie, C.A.; Aradhya, M.; Luo, M.C.; et al. Genome-wide SNP discovery in walnut with an AGSNP pipeline updated for SNP discovery in allogamous organisms. BMC Genom. 2012, 13, 354. [CrossRef] [PubMed]

49. Sun, C.; Wang, B.; Yan, L.; Hu, K.; Liu, S.; Zhou, Y.; Guan, C.; Zhang, Z.; Li, J.; Zhang, J.; et al. Genome-wide association study provides insight into the genetic control of plant height in rapeseed (Brassica napus L.). Front. Plant Sci. 2016, 7, 1102. [CrossRef] [PubMed]

50. Lamesch, P.; Berardini, T.Z.; Li, D.; Swarbreck, D.; Wilks, C.; Sasidharan, R.; Muller, R.; Dreher, K.; Alexander, D.L.; Garcia-Hernandez, M.; et al. The Arabidopsis Information Resource (TAIR): Improved gene annotation and new tools. Nucleic Acids Res. 2012, 40, D1202-D1210. [CrossRef] [PubMed]

51. You, F.M.; Li, P.; Kumar, S.; Ragupathy, R.; Li, Z.; Fu, Y.-B.; Cloutier, S. Genome-wide identification and characterization of the gene families controlling fatty acid biosynthesis in flax (Linum usitatissimum L.). J. Proteom. Bioinf. 2014, 7, 310-326.

52. Vrinten, P.; Hu, Z.; Munchinsky, M.A.; Rowland, G.; Qiu, X. Two FAD3 desaturase genes control the level of linolenic acid in flax seed. Plant Physiol. 2005, 139, 79-87. [CrossRef] [PubMed]

53. Soto-Cerda, B.J.; Duguid, S.; Booker, H.; Rowland, G.; Diederichsen, A.; Cloutier, S. Association mapping of seed quality traits using the Canadian flax (Linum usitatissimum L.) core collection. Theor. Appl. Genet. 2014, 127, 881-896. [CrossRef] [PubMed] 
54. You, F.M.; Li, P.; Ragupathy, R.; Kumar, S.; Zhu, T.; Luo, M.-C.; Duguid, S.D.; Rashid, K.Y.; Booker, H.M.; Deyholos, M.K.; et al. The Draft Flax Genome Pseudomolecules. In Proceedings of the 66th Flax Institute of the United States, Fargo, ND, USA, 31 March-1 April 2016; pp. 17-24.

55. Banik, M.; Duguid, S.; Cloutier, S. Transcript profiling and gene characterization of three fatty acid desaturase genes in high, moderate, and low linolenic acid genotypes of flax (Linum usitatissimum L.) and their role in linolenic acid accumulation. Genome 2011, 54, 471-483. [CrossRef] [PubMed]

56. Zhang, J.; Song, Q.; Cregan, P.B.; Nelson, R.L.; Wang, X.; Wu, J.; Jiang, G.L. Genome-wide association study for flowering time, maturity dates and plant height in early maturing soybean (Glycine max) germplasm. BMC Genom. 2015, 16, 217. [CrossRef] [PubMed]

57. Zhang, W.K.; Wang, Y.J.; Luo, G.Z.; Zhang, J.S.; He, C.Y.; Wu, X.L.; Gai, J.Y.; Chen, S.Y. QTL mapping of ten agronomic traits on the soybean (Glycine max L. Merr.) genetic map and their association with EST markers. Theor. Appl. Genet. 2004, 108, 1131-1139. [CrossRef] [PubMed]

58. Eskandari, M.; Cober, E.R.; Rajcan, I. Genetic control of soybean seed oil: Ii. QTL and genes that increase oil concentration without decreasing protein or with increased seed yield. Theor. Appl. Genet. 2013, 126, 1677-1687. [CrossRef] [PubMed]

59. Hwang, E.Y.; Song, Q.; Jia, G.; Specht, J.E.; Hyten, D.L.; Costa, J.; Cregan, P.B. A genome-wide association study of seed protein and oil content in soybean. BMC Genom. 2014, 15, 1. [CrossRef] [PubMed]

60. Yang, J.; Benyamin, B.; McEvoy, B.P.; Gordon, S.; Henders, A.K.; Nyholt, D.R.; Madden, P.A.; Heath, A.C.; Martin, N.G.; Montgomery, G.W.; et al. Common SNPs explain a large proportion of the heritability for human height. Nat. Genet. 2010, 42, 565-569. [CrossRef] [PubMed]

61. Yang, J.; Lee, S.H.; Goddard, M.E.; Visscher, P.M. GCTA: A tool for genome-wide complex trait analysis. Am. J. Hum. Genet. 2011, 88, 76-82. [CrossRef] [PubMed]

62. Yang, J.; Bakshi, A.; Zhu, Z.; Hemani, G.; Vinkhuyzen, A.A.E.; Lee, S.H.; Robinson, M.R.; Perry, J.R.B.; Nolte, I.M.; van Vliet-Ostaptchouk, J.V.; et al. Genetic variance estimation with imputed variants finds negligible missing heritability for human height and body mass index. Nat. Genet. 2015, 47, 1114-1120. [CrossRef] [PubMed]

63. Yang, J.; Manolio, T.A.; Pasquale, L.R.; Boerwinkle, E.; Caporaso, N.; Cunningham, J.M.; de Andrade, M.; Feenstra, B.; Feingold, E.; Hayes, M.G.; et al. Genome partitioning of genetic variation for complex traits using common SNPs. Nat. Genet. 2011, 43, 519-525. [CrossRef] [PubMed]

64. Wood, A.R.; Esko, T.; Yang, J.; Vedantam, S.; Pers, T.H.; Gustafsson, S.; Chu, A.Y.; Estrada, K.; Luan, J.; Kutalik, Z.; et al. Defining the role of common variation in the genomic and biological architecture of adult human height. Nat. Genet. 2014, 46, 1173-1186. [CrossRef] [PubMed]

65. Duguid, S.D.; Kenaschuk, E.O.; Rashid, K.Y. Macbeth flax. Can. J. Plant Sci. 2003, 83, 803-805. [CrossRef]

66. Rowland, G.G.; Hormis, Y.A.; Rashid, K.Y. CDC bethune flax. Can. J. Plant Sci. 2002, 82, 101-102. [CrossRef]

67. Rowland, G.G.; Bhatty, R.S. Ethyl meththane-sulphonate induced fatty acid mutations in flax. J. Am. Oil Chem. Soc. 1990, 67, 213-214. [CrossRef]

68. You, F.M.; Huo, N.; Deal, K.R.; Gu, Y.Q.; Luo, M.C.; McGuire, P.E.; Dvorak, J.; Anderson, O.D. Annotation-based genome-wide SNP discovery in the large and complex Aegilops tauschii genome using next-generation sequencing without a reference genome sequence. BMC Genom. 2011, 12, 59. [CrossRef] [PubMed]

69. Li, H.; Handsaker, B.; Wysoker, A.; Fennell, T.; Ruan, J.; Homer, N.; Marth, G.; Abecasis, G.; Durbin, R. The sequence alignment/map format and SAMtools. Bioinformatics 2009, 25, 2078-2079. [CrossRef] [PubMed]

70. Browning, S.R.; Browning, B.L. Rapid and accurate haplotype phasing and missing-data inference for whole-genome association studies by use of localized haplotype clustering. Am. J. Hum. Genet. 2007, 81, 1084-1097. [CrossRef] [PubMed]

71. Purcell, S.; Neale, B.; Todd-Brown, K.; Thomas, L.; Ferreira, M.A.; Bender, D.; Maller, J.; Sklar, P.; de Bakker, P.I.; Daly, M.J.; et al. Plink: A tool set for whole-genome association and population-based linkage analyses. Am. J. Hum. Genet. 2007, 81, 559-575. [CrossRef] [PubMed]

72. Hill, W.G.; Weir, B.S. Variances and covariances of squared linkage disequilibria in finite populations. Theor. Popul. Biol. 1988, 33, 54-78. [CrossRef]

73. Pfeifer, B.; Wittelsburger, U.; Ramos-Onsins, S.E.; Lercher, M.J. Popgenome: An efficient swiss army knife for population genomic analyses in R. Mol. Biol. Evol. 2014, 31, 1929-1936. [CrossRef] [PubMed] 
74. Jombart, T.; Devillard, S.; Balloux, F. Discriminant analysis of principal components: A new method for the analysis of genetically structured populations. BMC Genet. 2010, 11, 94. [CrossRef] [PubMed]

75. Jombart, T. Adegenet: A R package for the multivariate analysis of genetic markers. Bioinformatics 2008, 24, 1403-1405. [CrossRef] [PubMed]

76. Lin, C.S.; Poushinsky, G. A modified augmented design (type 2) for rectangular plots. Can. J. Plant Sci. 1985, 65, 743-749. [CrossRef]

77. You, F.M.; Duguid, S.D.; Thambugala, D.; Cloutier, S. Statistical analysis and field evaluation of the type 2 modified augmented design (MAD) in phenotyping of flax (Linum usitatissimum) germplasms in multiple environments. Aust. J. Crop Sci. 2013, 7, 1789-1800.

78. Association of Official Analytical Chemists. Fat (total, saturated and unsaturated) in foods: Hydrolytic extraction gas chromatographic method. In Official Methods of Analysis of AOAC International, 18th ed.; Horwitz, W., Ed.; AOAC International: Gaithersburg, MD, USA, 2001.

79. Bates, D.; Maechler, M.; Bolker, B.; Walker, S. Fitting linear mixed-effects models using lme4. J. Stat. Softw. 2015, 67, 1-48. [CrossRef]

80. Zhang, Z.; Ersoz, E.; Lai, C.Q.; Todhunter, R.J.; Tiwari, H.K.; Gore, M.A.; Bradbury, P.J.; Yu, J.; Arnett, D.K.; Ordovas, J.M.; et al. Mixed linear model approach adapted for genome-wide association studies. Nat. Genet. 2010, 42, 355-360. [CrossRef] [PubMed]

81. Yu, J.; Pressoir, G.; Briggs, W.H.; Vroh Bi, I.; Yamasaki, M.; Doebley, J.F.; McMullen, M.D.; Gaut, B.S.; Nielsen, D.M.; Holland, J.B.; et al. A unified mixed-model method for association mapping that accounts for multiple levels of relatedness. Nat. Genet. 2006, 38, 203-208. [CrossRef] [PubMed]

82. Bradbury, P.J.; Zhang, Z.; Kroon, D.E.; Casstevens, T.M.; Ramdoss, Y.; Buckler, E.S. Tassel: Software for association mapping of complex traits in diverse samples. Bioinformatics 2007, 23, 2633-2635. [CrossRef] [PubMed]

83. Turner, S.D. Qqman: An R package for visualizing GWAS results using Q-Q and manhattan plots. biorXiv 2014. [CrossRef]

84. Thambugala, D.; Duguid, S.; Loewen, E.; Rowland, G.; Booker, H.; You, F.M.; Cloutier, S. Genetic variation of six desaturase genes in flax and their impact on fatty acid composition. Theor. Appl. Genet. 2013, 126, 2627-2641. [CrossRef] [PubMed] 